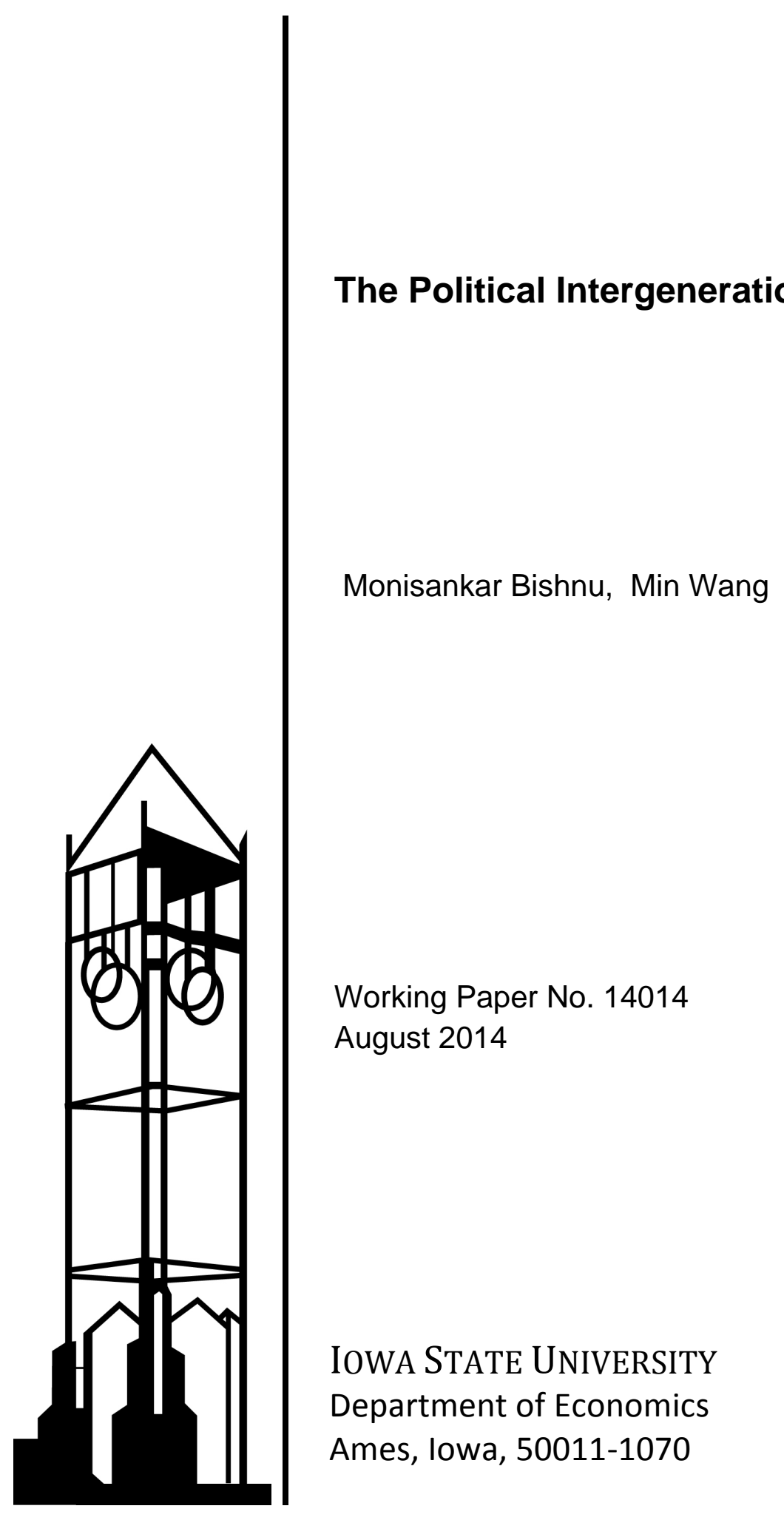

lowa State University does not discriminate on the basis of race, color, age, religion, national origin, sexual orientation, gender identity, genetic information, sex, marital status, disability, or status as a U.S. veteran. Inquiries can be directed to the Director of Equal Opportunity and Compliance, 3280 Beardshear Hall, (515) 294-7612. 


\title{
The Political Intergenerational Welfare STATE
}

\author{
Monisankar Bishnu \\ Min Wang \\ Australian National University and \\ Iowa State University* \\ Peking University, Beijing ${ }^{\dagger}$
}

August 1, 2014

\begin{abstract}
This paper characterizes an intergenerational welfare state with endogenous education and pension choice under general equilibrium-probabilistic voting. We show that politically implementing public education program always increases the future human capital, but this higher future human capital would not help support a more generous social security in the future. The effect of implementing PAYG social security on education however crucially depends on the sources of funding for education investment. Establishing PAYG pension program depresses investment in public education. However if the source of funding for education investment is private, in both the cases when pension is the only instrument or when public pension and public education are implemented together as a package, there can be an improvement in education investment if and only if the political influence of the old is limited and so the size of the PAYG social security is small. A substantially thick pension scheme which results from a heavy influence of the old in the political process spoils the mutual benefits.
\end{abstract}

Keywords : Education, Pension, Probabilistic voting, Markov Perfect Equilibrium, Endogenous growth

JEL Classification: E6, H3, H52, H55, D90

${ }^{*}$ Department of Economics, 479 Heady Hall, Iowa State University, Ames, IA - 50011, USA. Email: mbishnu@iastate.edu/mbishnu@gmail.com.

${ }^{\dagger}$ China Center for Economic Research, National School of Development, Peking University, Beijing 100871, China, Email: wangmin@nsd.pku.edu.cn. 


\section{Introduction}

Almost in all countries throughout the world, the population is aging over time. More particularly, the developed countries will be the first to face the challenges of this demographic change, as their older population - persons 65 years or older - will on average reach one fourth of their total population in three decades (See Figure 1). It is beyond any doubt that the pay-as-you-go (PAYG ) financed social security will be at the heart of the challenges that are being thrown by the demographic changes, and concern about the future solvency of the social security program has already resulted in a heated public policy debate (see Cooley and Soares (1999), Boldrin and Rustichini (2000), Feldstein (2005) and Gonzalez-Eiras and Niepelt (2008) for example). Most of the papers in the literature concentrate on social security in isolation, however, there are some studies (see for e.g., Pogue and Sgontz (1977), Becker and Murphy (1988) among the earlier works and more recently Rangel (2003), Boldrin and Montes (2005) among others) that emphasize that the other elements of the welfare state, particularly the forward channel, namely the education subsidy, should not be ignored. Aging population in the meanwhile also changes the pattern of the intergenerational distribution of social expenditure. Bringing the two-armed intergenerational transfers into the analysis not only makes the understanding of the functioning of welfare state more accurate and complete, but also reveals some interesting features of the welfare state.

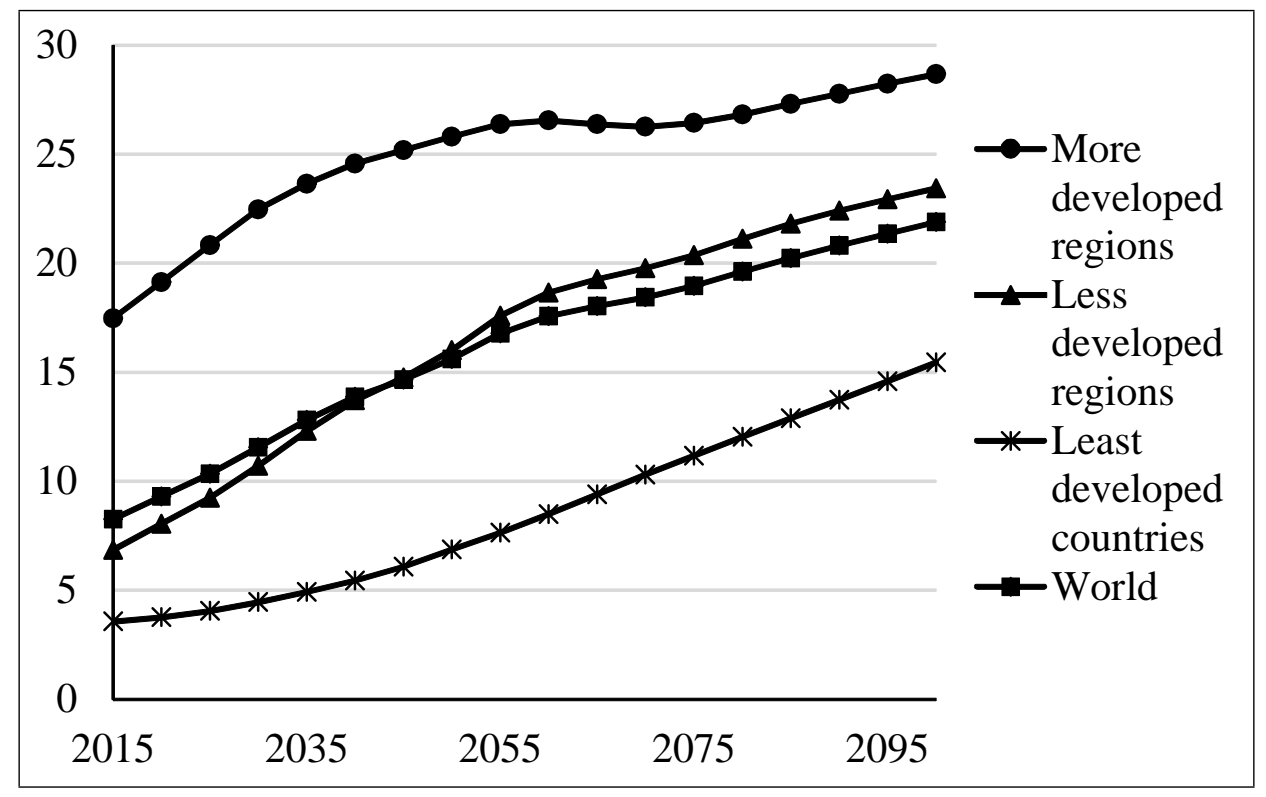

Figure 1: Population ages 65 and above (\% of total), 2015-2100

(Data source: World Population Prospects: The 2012 Revision, United Nations)

This paper presents a comprehensive analysis when education and PAYG social security, the two largest public programs in most economies, are politically determined. We particularly focus on intergenerational cooperation and conflict as well as the general equilibrium effects of 
any policy decision that originates from a voting outcome and show that both these factors have serious consequences on the states of the economy, i.e., the physical and human capital, the two important engines of the growth. Since both education subsidy and pension are funded by the working population, the generosity of these two programs is subject to intergenerational cooperation and conflict, and the social expenditure distribution hinges on the intergenerational distribution of political power. ${ }^{1}$ Further in the political economy, agents take prices as given when acting as consumers, but as rational voters, they internalize the general equilibrium effect of the policy choice on factor prices. As we proceed, it will become evident that the general equilibrium effects not only may help support the social security program, but also generate a clear distinction between the effects of public and private investment in education. Further, they also explain why the presence of PAYG social security may not provide sufficient incentive for education investment.

Apart from other issues, the present study also explores some of the interesting and timely relevant questions such as whether the existence of social security could increase the incentive of current working population to expand public investment in education, or as public education program provides more generous funding in education investment, whether the enhanced future productivity through augmenting education could help reduce the size of the social security program, or more importantly whether a relatively recent suggestion of Boldrin and Montes (2005), that education-social security should be implemented as a package, can survive under the growing influence of the old in the political process.

The framework we consider is a standard three-period overlapping generations economy embedded with probabilistic voting. The voting power is distributed intergenerationally and the vote-seeking candidates need to cater to the interests of all voters during the electoral competition. Voters hold rational expectations and are allowed to sequentially choose the policies. We focus on the Markov Perfect Equilibrium (henceforth MPE) of the voting outcomes. ${ }^{2}$ Our choice of probabilistic voting is driven by its simplicity and we depend on MPE for obtaining analytical results. But the additional gain from a probabilistic voting setup is that it can capture intergenerational cooperation and conflict, which is indeed the nature of competition between education subsidy and social security. Here, the dynamic politico-economic equilibria are founded on competitive equilibrium with subgame perfect tax rates and transfers since the

\footnotetext{
${ }^{1}$ As argued by Mulligan and Sala-i-Martin (1999), the political clout of the old people has grown beyond what was predicted by the evolution of the demographics. They interpret the data in favor of the old as a political power enjoyed by those citizens (also see Preston (1984), Lindert (1994)). As is mentioned in Song, Storesletten and Zilibotti (2012), the voter's turnout in the US is falling however, the participation of the old is increasing. Further, they report that the share of vote cast by voters of $61+$ age is expected to reach $50 \%$ by the year 2050 in the OECD countries. These phenomena well explain that in the voting framework, the equations are changing rapidly. These information may explain why even with significant pressure on pension funds, the idea of lowering the tax rate has not been considered by the researchers as such a policy would have a very small chance of success in reality.

${ }^{2}$ For a discussion on MPE in overlapping generations framework, see Bhaskar (1998), Gonzalez-Eiras and Niepelt (2008) among others.
} 
voters are not bound by their past political decisions. This complete analysis provides some important results that are worth noting and summarized below.

Our first observation conveys an important message that under MPE, establishing public education program by probabilistic voting increases human capital but reduces physical capital accumulation. This happens because in our model, rational voters take into account the positive general equilibrium effects of education investment that materialize in their life-span and therefore would support for a more generous funding for education compared to a situation when the funding for education is private and therefore not politically determined. This result naturally implies that when the production technology is more human capital intensive, it may increase the long run growth rate. More importantly, this higher level of public education program (higher compared to the case when education is privately funded) however does not guarantee a more generous social security. In fact we have been able to show that the generosity of social security becomes lower in a logarithmic setup, despite the fact that the education level is higher than before. This finding has a strikingly strong implication. It implies that the existing wisdom that when PAYG social security is present, introducing a forward intergenerational good, namely publicly funded education, can be helpful since it enhances future productivity, cannot hold under the political economy setup.

A separately significant result of the paper reveals some of the important characteristics of a two-armed welfare state. Firstly, we show that when public education program has already been established, infusing a PAYG social security program will compete with public education program for government revenue and crowd out public investment in education, depressing the human capital accumulation. However, later we show that in a laissez-faire economy with privately funded education, politically establishing the PAYG social security program, either independently or together with a public education program as a package, increases human capital accumulation if the political influence of the old is limited and therefore the size of the pension program is also limited. This happens because the small-sized PAYG social security, as will be shown, can expand the family budget available for education investment. A substantially thick pension which results from heavy influence of the old, however, spoils this mutual benefit.

Let us explain why the first result mentioned in the previous paragraph is of our interest. According to Pogue and Sgontz (1977), PAYG social security creates incentives for public investment in education. Becker and Murphy (1988) also suggests that PAYG social security strengthens the political support among the current working agents for public investment in education. Their study connects education investment made by the parents with social security by considering this as a trade among generations: children receive education from their parents and in exchange pay for their old age benefits. In a relatively recent work, Rangel (2003) also focuses on the issue of sustainability when both forward and backward intergenerational goods are present and shows that backward intergenerational goods (BIGs), such as social security, play a crucial role in sustaining investment in forward intergenerational goods (FIGs) 
like education: without them investment is inefficiently low, but with them optimal investment is possible. In contrast to these partial equilibrium studies, Soares (2006) in a calibrated general equilibrium OLG framework finds that infusing a PAYG system exogenously results in a political equilibrium with lower funding for public education compared to the case when social security is absent. This happens because, under PAYG scheme, the increased incentive in investing in young's education to expand future wage bill is cancelled out by the increase in future interest rate, and thus the public education investment has no direct positive effect on the present value of social security benefits (Kaganovich and Zilcha, 2012). Our first result mentioned in the preceding paragraph further confirms that their result holds even when PAYG social security is endogenously determined. Below we explain the importance of the later result that we have mentioned in the previous paragraph.

In Boldrin and Montes (2005), simultaneous existence of public education and PAYG social security is justified as a means to implement an intergenerational transfer scheme that replicates complete market allocations. ${ }^{3}$ In our political economy setup, if the same question arises as to whether a simultaneous arrangement of these two-armed intergenerational transfers is justifiable for the long run growth, the answer would depend on the intergenerational distribution of political power and thus this particular result can be considered as a political economy version of Boldrin and Montes (2005). ${ }^{4}$ An important result in this intergenerational transfer literature is Rangel (2003) where an education - pension package can be supported by trigger strategy argument which demands a continuation surplus. Therefore a heavy backward payment incentivise investment in the forward arm. Our model points out that a sufficiently heavy backward transfer cannot be cost less - it reduces the generosity of the forward arm and therefore, a sufficiently heavy social security along with education subsidy as a package may end up with a lower level of education and upset the mutual benefit from these two intergenerational instruments. We show that a heavy influence of the old in the political process can guarantee a thick pension but will reduce investment in education and therefore spoil the entire

\footnotetext{
${ }^{3}$ Wang (2013) extends their study by endogenizing the imperfection of the credit market and shows that the result could hold even when borrowing constraints for education loan arise endogenously. In another interesting work, Andersen and Bhattacharya (2013) show that when the young must borrow to make the education investment and the economy is dynamically efficient, the golden rule level of human capital is higher than that is achievable with complete education-loan markets alone. Further, they show that a carefully designed education-pension welfare package can achieve efficient education investment, and owing to the intergenerational human capital externality, the pension component of such a package will be entirely phased out eventually.

${ }^{4}$ According to Docquier, Paddison and Pestieau (2007), the definition of optimality in Boldrin and Montes (2005) framework is restrictive because the study disregards the effect of externality in education. They show that because of the externalities, allocations of human and physical capital in competitive equilibrium differ from the planner's and a possibility naturally arises where the laissez-faire equilibrium experiences higher physical capital accumulation but lower human capital accumulation compared to the planner's allocations. However, Bishnu (2013) shows that if the origin of non-optimality of human capital accumulation is consumption externality, the possibility that the accumulation of human and physical capital in a laissez-faire will differ from the planner's in an opposite direction is not at all feasible. This observation not only has crucial implication on pension and education subsidy but also can justify government intervention in education even in the absence of education externalities.
} 
mutual benefits from the existence of two intergenrational transfers. As a whole, ignoring the intergenerational political influence when considering channelizing funds will be a mistake if policy implementations are considered under intergenerational conflicts, especially when the influence of the aged is steadily increasing. The present paper can also be seen from an angle where Gonzalez-Eiras and Niepelt (2008) appears as one of the special cases in which education is truncated from the analysis. ${ }^{5}$ Naturally, in this light, the present paper seems more complete and has the flexibility to compare all the situations, specifically both private and public channels of investment in education and PAYG social security.

Here we must mention some other papers that also study education and social security in unison and thus are related to our study. Kaganovich and Zilcha (1999) consider an economy with altruistically-motivated parents who invest in the human capital of their children, and analyze how the allocation of the tax revenues between public education and social security affects growth and welfare. In their study, however, the total tax rate is artificially fixed and the allocation of tax revenue is determined by a growth maximization problem. Pecchenino and Utendorf (1999) study the impact of PAYG social security on incentives for private investment in education and show that in an aging economy, social security may crowd out education investment and thus reduce growth and social welfare. Poutvaara (2006) uses trigger strategies to characterize the political equilibrium of social security and public education in an economy where agents are heterogeneous and decisions are taken by majority voting. In an open economy framework with fixed factor prices, Naito (2012) also focuses on the sustainability of public education and social security under probabilistic voting setup and investigates the interaction between these two policies with economic growth. However in his study, the proportion of expenditure on one program to the total expenditure is artificially fixed at some level. Kaganovich and Zilcha (2012) study a political economy in which public education is determined through a voting process but the social security tax rate is exogenously given. They show that compared to PAYG, the fully funded social security system produces political support for a relatively higher education funding, and hence generates higher rates of physical and human capital accumulation and economic growth. In a very recent study, Ono (2013) incorporates longevity as well as altruism and allows voting on both social security and publicly funded education. Other two papers that need to be mentioned are Gonzalez-Eiras and Niepelt (2012) and Lancia and Russo (2013). While the first one analyses the effect of demographic aging and retirement on long term growth, the second one focuses only on the characterization of general equilibrium.

\footnotetext{
${ }^{5}$ The paper that is technically close to ours is Gonzalez-Eiras and Niepelt (2008) which deals with a probabilistic voting model (only on pension) with population growth in which they take into account the general equilibrium effects of the existing policy on the future outcome. Though we do not consider any population growth, the essence of changing population is captured through the distribution of intergenerational voting power. Song (2011) focuses on within generation heterogeneity and analyzes the interaction between social security transfers and wealth inequality. He finds that higher inequality is associated with higher equilibrium social security tax rates if social security redistributes within cohorts. This paper too relies on probabilistic voting and uses MPE, however like Gozalez-Eiras and Niepelt (2008), ignores the education channel of transfers.
} 
Our paper captures the political economy more broadly and comprehensively when preferences are altruistic. Some of the earlier studies that considered the link between public education and public social security are Richman and Stagner (1986), Cremer, Kessler and Pestieau (1992) among others.

Thus by comparing the effects of the two different sources of funding for education (both separately and in unison) along with PAYG in a political economy framework, where both the intergenerational conflict and the general equilibrium effects are considered, the present paper certainly distinguishes itself from the existing literature. The study not only provides a comprehensive analysis which was somehow ignored in the literature, it also clearly suggests that a partial framework that ignores the crucial effects mentioned above may produce different results.

The rest of the paper is organized as follows. Section 2 presents the baseline model, that is, the laissez-faire economy. In section 3, we present three voting scenarios where different instruments are politically determined through a probabilistic voting. Section 4 deals with the policy implication of the intergenerational transfers and we present our main results there. While section 5 concludes, proofs are presented in the Appendix.

\section{Laissez-faire Economy}

We consider an economy that consists of an infinite sequence of three-period lived overlapping generations, an initial old generation and an initial middle-aged generation. In each generation, there is a continuum of identical agents of measure one. ${ }^{6}$ Agents receive education when young, while they work and carry out decisions of consumption, saving and education investment for their children during middle age. When they are old, the agents retire and consume out of the total return on their savings. An agent who is working at period $t$, that is a middle-aged agent in $t$, is called a generation- $t$ agent.

Denote by $h_{t}$ the human capital of an individual belonging to generation $t$. The human capital of a generation $t+1$ agent is a function of the educational expenditure $e_{t}$ she makes when young and her parent's human capital $h_{t}$, the endowment of basic knowledge she is born with. We assume the human capital is produced by a constant-return-to-scale technology is given by $h_{t+1}=h\left(e_{t}, h_{t}\right)=B e_{t}^{\beta} h_{t}^{1-\beta}, B>0, \beta \in(0,1){ }^{7}$ There is a single final good produced with a constant returns to scale production function $F\left(K_{t}, H_{t}\right)$, where $K_{t}$ and $H_{t}$

\footnotetext{
${ }^{6}$ If we introduce population growth, the political weight of the old, the variable that reflects the intergnerational distribution of political power and will be defined later, becomes $\omega /\left(1+n_{t}\right)$, where $n_{t}$ is the population growth rate at period $t$. To focus on the effects of intergenerational distribution of political power on the welfare states and also to get the analytical results, we for simplicity make this constant population assumption and therefore disentangle the effects of distribution of political power from that of population growth.

${ }^{7}$ Most of our results hold for a human capital specification that abstracts from generational human capital externalities, that is, where $h_{t+1}$ depends on $e_{t}$ only.
} 
are aggregate physical capital and human capital respectively at $t$. Defining $k_{t} \equiv K_{t} / N_{t}$ and $h_{t} \equiv H_{t} / N_{t}$ in which $N_{t}$ is the population of generation- $t$ agents, output per middle-aged agent at time $t$ can be expressed as an intensive form $f\left(k_{t}, h_{t}\right)=F\left(k_{t}, h_{t}\right)$. We assume that $f$ takes the Cobb-Douglas form, i.e., $f\left(k_{t}, h_{t}\right)=A k_{t}^{\alpha} h_{t}^{1-\alpha}, A>0, \alpha \in(0,1)$. Since the measure of the members of each generation is one, we know $N_{t}=1$ and thus $k_{t}=K_{t}$ and $h_{t}=H_{t}$. The final good can either be consumed in the period it is produced, or it can be saved to provide capital in the following period. Capital is conveniently assumed to depreciate fully between periods. Young agents supply labor inelastically in competitive labor markets, earning a wage of $w_{t}=\partial f\left(k_{t}, h_{t}\right) / \partial h_{t}=(1-\alpha) A k_{t}^{\alpha} h_{t}^{-\alpha}$ at time $t$; similarly, capital is traded in competitive capital markets, and earns a gross real return of $R_{t+1}$ between $t$ and $t+1$ where $R_{t}=\partial f\left(k_{t}, h_{t}\right) / \partial k_{t}=\alpha A k_{t}^{\alpha-1} h_{t}^{1-\alpha}$.

We assume a generation- $t$ agent draws utility from $\left(c_{t}^{m}, c_{t+1}^{o}, h_{t+1}\right)$, the terms in the parenthesis denoting consumption at middle age and old age, and the level of human capital of her children respectively. More specifically, the life-time utility for a generation- $t$ agent is

$$
\mathcal{U} \equiv u\left(c_{t}^{m}\right)+\delta\left[u\left(c_{t+1}^{o}\right)+\phi u\left(h_{t+1}\right)\right]
$$

where $\delta \in(0,1)$ is the standard discount factor and $\phi \in(0,1)$ represents the relative weight assigned to the utility that an old agent enjoys from her children's human capital, expressing parents' altruism towards their offspring. ${ }^{8}$ Instantaneous utility function $u$ is continuously differentiable, strictly increasing and strictly concave. An agent when middle-aged allocates her labor income among consumption, saving and investment in education for her children. ${ }^{9}$ Saving $s_{t}$ while middle-aged returns $s_{t} R_{t+1}$ in the next period when the agent is old. These imply that $c_{t}^{m}=w_{t} h_{t}-s_{t}-e_{t}$ and $c_{t+1}^{o}=s_{t} R_{t+1}$. Thus given the factor prices, human capital production technology $h_{t}=h\left(e_{t-1}, h_{t-1}\right)$ and the budget constraints stated above, when a generation $-t$ agent maximizes her utility (1) with respect to $\left\{s_{t}, e_{t}\right\}$, we arrive at the following first order

\footnotetext{
${ }^{8}$ Utility specification that represents altruism through the level of human capital of the next generation is very common and vastly used in the literature. Our specification is simple and standard, for example, as in Kaganovich and Zilcha (1999), Pecchenino and Utendorf (1999) Glomm and Kaganovich (2003, 2008) and in line with Glomm and Ravikumar (1992), De la Croix and Doepke (2003) among others.

${ }^{9} \mathrm{As}$ is common treatment in the literature, we, in this paper, do not bring a credit market that can fund education for the young. The entire discussion here are on two sources of funding, private investment (made by parents) and public investment (made by the government), due to the following considerations. First, these two sources are the main sources of funds in any economy. Second, owing to the inalienability of human capital, future labor income cannot be collateralized and credit markets severely restrict any borrowing against future human capital for education purposes. A credit market for education loan even does not exist in most developing countries, e.g., China or trivially thin as in India. Third, the present setup allows us to derive analytical results.
} 
conditions $^{10}$ :

$$
\begin{aligned}
u^{\prime}\left(w_{t} h_{t}-s_{t}^{L}-e_{t}^{L}\right) & =\delta R_{t+1} u^{\prime}\left(R_{t+1} s_{t}^{L}\right) \\
u^{\prime}\left(w_{t} h_{t}-s_{t}^{L}-e_{t}^{L}\right) & =\delta \phi u^{\prime}\left(h_{t+1}\right) \frac{\partial h\left(e_{t}^{L}, h_{t}\right)}{\partial e_{t}^{L}} .
\end{aligned}
$$

While equation (2) represents the optimal intertemporal consumption allocation, that is the standard Euler's equation, (3) indicates that the marginal sacrifice in utility from investing in education of the descendents is equal to the marginal benefit from utility gain adjusted to the gain in the level of human capital of their descendents. To derive closed-form solutions of political equilibrium and economic growth, we must impose functional form restrictions on the utility function (1). Specifically, we assume that the utility function is logarithmic. By solving the above two first order conditions, we get the following:

$$
e_{t}^{L}=\frac{\beta \delta \phi}{1+\delta+\beta \delta \phi} w_{t} h_{t}
$$

and

$$
s_{t}^{L}=\frac{\delta}{1+\delta+\beta \delta \phi} w_{t} h_{t}
$$

Using the above along with the equilibrium factor prices and the fact that the generalequilibrium condition $k_{t+1}=s_{t}$ holds at every $t$, we obtain a two-dimensional first-order dynamical system of this economy, given by $k_{t+1}^{L}=\delta(1-\alpha) A k_{t}^{\alpha} h_{t}^{1-\alpha} /(1+\delta+\beta \delta \phi)$ and $h_{t+1}^{L}=B[\beta \delta \phi A(1-\alpha) /(1+\delta+\beta \delta \phi)]^{\beta} k_{t}^{\alpha \beta} h_{t}^{1-\alpha \beta}$. Given $k_{0}$ and $h_{0}$, all the dynamic competitive equilibria are characterized by the sequences of $\left\{k_{t}^{L}, h_{t}^{L}\right\}$ that satisfy the two equilibrium paths expressed above. Given this dynamical system, we complete our characterization for this laissez-faire economy by focusing on the steady state equilibrium and thus we have the following lemma:

Lemma 1 In the laissez-faire economy, there exists an unique steady state with balanced growth where the human and physical capital grow at a same constant rate.

\section{Political Economy}

In this section we consider the same framework as before but introduce two oppositely directed policies, namely public education and PAYG social security to investigate the roles they play in an economy. We bring these two intergenerational welfare states through a political process

\footnotetext{
${ }^{10}$ Superscript $L$ represents the optimal and equilibrium values of the concerned variables in the laissez-faire economy. Similarly, the superscripts $G, P$ and $X$ are used to represent the optimal and equilibrium values of the concerned variables in the political economy of public education, political economy of pension and political economy of two-armed intergenerational transfers analysis as in subsections $3.1,3.2$, and 3.3 respectively.
} 
which runs under a probabilistic voting framework (see Lindbeck and Weibull (1987)), and the economy politically determines the size of these programs to be implemented.

In particular, we investigate three political economies. The choices of the political economies are such that we can get a complete understanding of all possible scenarios. The first scenario is the Political economy of public education presented in subsection 3.1. In this economy, the only political decision made by the agents is to determine the level of public investment in education. That is, the government collects tax revenue from the middle-aged agents and channelizes it to the present young to provide funds for their education. The second scenario is the Political economy of social security which is presented in subsection 3.2. This economy deals with another instrument of welfare state but it is a backward intergenerational good, namely social security. However, in this case, we keep the source of education funding private as in the laissez-faire economy, but introduce public social security benefit in the form of a politically determined PAYG social security. The last two scenarios bring out the effects of the instruments when they are present in an economy in isolation. Thus, as a last policy experiment, in the Political economy of two-armed intergenerational transfers, we bring both of the two instruments together through a political process that simultaneously determines these two intergenerational goods. With these three policy environments and the laissez-faire economy presented above, we can not only explore the political equilibrium of public education and PAYG social security, but can also examine their roles in all possible scenarios.

\subsection{Political Economy of Public Education}

We first consider a modification of the laissez-faire economy, where social security is absent but the agents politically determine the size of the public education program. Suppose the government imposes a proportional tax rate $\theta_{t}$ at each $t$ on the income earned by each of the generation $-t$ agents when they are middle-aged to finance the public education program for the present young. The fiscal program of subsidy needs to satisfy the period-wise balanced budget condition, i.e., $e_{t}=\theta_{t} w_{t} h_{t}$. The tax rate $\theta_{t}$ is determined by a repeated political process (to be discussed below in detail) at the beginning of each period. After the political process of voting is complete and the education tax rate is set, agents make their decisions on consumption and savings. Given the factor prices, education policies and the human capital production technology, a generation- $t$ agent's optimization problem now is to maximize (1) subject to $c_{t}^{m}=\left(1-\theta_{t}\right) w_{t} h_{t}-s_{t}$ and $c_{t+1}^{o}=s_{t} R_{t+1}$. Then given $\theta_{t}$, the first order condition with respect to $s_{t}$ is given by

$$
u^{\prime}\left[\left(1-\theta_{t}\right) w_{t} h_{t}-s_{t}^{G}\right]=\delta R_{t+1} u^{\prime}\left(R_{t+1} s_{t}^{G}\right)
$$


which ensures the optimal saving

$$
s_{t}^{G}=\frac{\left(1-\theta_{t}\right) \delta w_{t} h_{t}}{1+\delta}
$$

Next, we solve the political equilibrium under a repeated voting process where only middleaged and old participate. Abiding by the standard practice as discussed earlier, we disallow the young's participation in the voting process due to age-restriction. At the beginning of each period, the contemporaneous tax rate is determined by a candidate who is democratically elected by all the current voters. We assume that the size of the program is determined in a probabilistic-voting framework. Under this political setting, there are two political candidates who are competing in an election. When deciding on which candidate to support, voters anticipate the effects of the candidate's policy platform on equilibrium prices, future's political decisions and their own welfare. As we mentioned earlier we focus on the MPE where agents can form perfect foresight on the policies which depend on the set of state variables of the economy. For rest of the analysis, we use the notation $S^{t}$ to denote the set of state variables in period $t$, i.e., $S^{t} \equiv\left\{k_{t}, h_{t}\right\}$. Since winning the election is the only aim of the candidates, in the probabilistic-voting Nash equilibrium, the two candidates seeking to maximize their vote shares propose the same policy platform. This policy platform maximizes a weighted average of the welfare of all voters, in which the weights assigned to different groups of voters reflect the size or the political power of different generations.

By the foregoing discussion, the political decision on the equilibrium education policy can be derived by maximizing the weighted sum of the indirect utilities of two generations, i.e.,

$$
\max _{\theta_{t} \in[0,1]} \mathcal{W}\left(\mathcal{S}^{t} ; \theta_{t}\right)=\omega V_{t}^{o}\left(\mathcal{S}^{t} ; \theta_{t}\right)+V_{t}^{m}\left(\mathcal{S}^{t} ; \theta_{t}\right)
$$

where $V_{t}^{m}$ and $V_{t}^{o}$ denote the welfare of the middle aged and the old respectively at period $t$ given the state $\mathcal{S}^{t}$. The parameter $\omega$ is the political weight assigned to the old relative to a middleaged by the political candidates. In line with the explanation by Song, Storesletten and Zilibotti (2012), this relative weight captures the relative political clout of each generation, reflecting, on one hand, its relative size and on the other hand, exogenous group-specific characteristics, such as the voting turnout or the salience of the fiscal policy for that group relative to other issues. In our model, the young receive education, but (7) shows that this particular generation is not allowed to vote and thus is completely dependent on others for investment in education. It should be noted that although the young have no role in the voting process, the middle-aged have an incentive to invest in education for the future generation since they directly derive utility out of the level of education accumulated by their descendents. Not only that, agents also could acquire higher returns on their saving in the next period through general equilibrium effects. 
To characterize the political decision on the public education investment, we first consider the welfare effect of this equilibrium education $\operatorname{tax} \theta_{t}$ on various groups of voters, i.e., the middle-aged workers and the old retirees. Evidently, the education tax $\theta_{t}$ imposed in period $t$ has no welfare effect on the current old, i.e., $\partial V_{t}^{o} / \partial \theta_{t}=0$. This follows directly from the fact that all the variables, i.e., $h_{t}, R_{t}$ and $s_{t-1}$, in the utility function of the old in period $t$, that is in $V_{t}^{o}=u\left(R_{t} s_{t-1}\right)+\phi u\left(h_{t}\right)$, are pre-determined in $t$. For the middle aged, the welfare effect of education tax is more complex. Differentiating $V_{t}^{m}(\cdot)$ with respect to $\theta_{t}$ yields

$$
\frac{\partial V_{t}^{m}}{\partial \theta_{t}}=\underbrace{-u^{\prime}\left(c_{t}^{m}\right) w_{t} h_{t}}_{\mathcal{A}}+\underbrace{\delta \phi u^{\prime}\left(h_{t+1}\right) \frac{\partial h_{t+1}}{\partial \theta_{t}}}_{\mathcal{B}}+\delta s_{t}^{G} u^{\prime}\left(c_{t+1}^{o}\right)(\underbrace{\frac{\partial R_{t+1}}{\partial k_{t+1}} \frac{\partial k_{t+1}}{\partial \theta_{t}}}_{\mathcal{C}}+\underbrace{\frac{\partial R_{t+1}}{\partial h_{t+1}} \frac{\partial h_{t+1}}{\partial \theta_{t}}}_{\mathcal{D}}) \text {. }
$$

Note that the effect of $\theta_{t}$ on the savings of the middle aged cancels out by the envelope theorem. The first negative term $\mathcal{A}$ reflects the cost of investment in public education. The second term $\mathcal{B}$ captures the positive effect of public education through tax enjoyed by the parental generation because of altruism. As previously discussed, the last two terms $\mathcal{C}$ and $\mathcal{D}$ reflect the general equilibrium effect of public education tax on the rate of interest through the channel of physical and human capital respectively. On one hand, by directing funds as a forward intergenerational good to the next generation, the education $\operatorname{tax} \theta_{t}$ reduces private savings in period $t$ and consequently also reduces the physical capital investment, which eventually leads to an increase in the rate of interest in the next period. That is, $\partial R_{t+1} / \partial k_{t+1}<0$ along with $\partial k_{t+1} / \partial \theta_{t}<0$. On the other hand, channelizing more funds towards the education of the next generation necessarily increases the level of human capital of the descendents, which in turn, also increases the rate of interest, i.e., $\partial R_{t+1} / \partial h_{t+1}>0$ along with $\partial h_{t+1} / \partial \theta_{t}>0 .{ }^{11}$ The aggregate general equilibrium effect of investment in public education is thus positive for the middle-aged workers with $\mathcal{C}>0$ and $\mathcal{D}>0$.

Under MPE, the equilibrium tax rate is the fixed point in $\theta_{t}\left(\mathcal{S}^{t}\right)=\arg \max _{\theta_{t} \in[0,1]} \mathcal{W}\left(\mathcal{S}^{t} ; \theta_{t}\right)$. We first substitute the factor prices, the equilibrium condition for market clearing and the private optimal savings $s_{t}^{G}$ given by $(6)$ into $\mathcal{W}\left(\mathcal{S}^{t} ; \theta_{t}\right)$. Then, by omitting the terms that are independent of the policy parameter $\theta_{t}$, the political objective function $\mathcal{W}\left(\mathcal{S}^{t} ; \theta_{t}\right)$ reduces to ${ }^{12}$

$$
\mathcal{W}\left(\mathcal{S}^{t} ; \theta_{t}\right) \simeq(1+\alpha \delta) \ln \left(1-\theta_{t}\right)+\beta \delta(1-\alpha+\phi) \ln \theta_{t} .
$$

By solving the first order condition of the above probabilistic-voting problem, i.e., by setting $\partial \mathcal{W}\left(\mathcal{S}^{t}, \theta_{t}\right) / \partial \theta_{t}=0$, we finally have the following lemma:

\footnotetext{
${ }^{11}$ Note that under our specific functional form of the human capital production, $\partial h_{t+1} / \partial \theta_{t}=$ $B \beta e_{t}^{\beta-1} h_{t}^{1-\beta} w_{t} h_{t}$.

${ }^{12} \mathrm{In}$ all that follows, we will use the notation $\simeq$ to denote the effective value function that contains the relevant fiscal parameter but not the other irrelevant terms.
} 
Lemma 2 In a political economy with public education determined in a probabilistic-voting setting, there exists an unique interior education tax rate $\theta^{G}$ under MPE and is given by

$$
\theta^{G} \equiv \frac{\phi \beta \delta+\beta \delta(1-\alpha)}{\Omega} \in(0,1) \forall t
$$

where $\Omega=1+\alpha \delta+\beta \delta(1-\alpha)+\beta \delta \phi>1$.

Lemma 2 shows that, under the logarithm utility, the equilibrium education tax is independent of the states of the economy and thus is constant over time. ${ }^{13}$ Using the equilibrium conditions and the balanced budget program of the government, the two-dimensional first-order dynamical system of this economy can be written as $k_{t+1}^{G}=\left[\delta A\left(1-\theta^{G}\right)(1-\alpha) /(1+\delta)\right] k_{t}^{\alpha} h_{t}^{1-\alpha}$ and $h_{t+1}^{G}=B\left[\theta^{G} A(1-\alpha)\right]^{\beta} k_{t}^{\alpha \beta} h_{t}^{1-\alpha \beta}$. Given $k_{0}$ and $h_{0}$, all dynamic, competitive equilibria are characterized by sequences of $\left\{k_{t}^{G}, h_{t}^{G}\right\}$ that satisfy the above two equilibrium paths. ${ }^{14}$

Finally we must mention that although we exclude from here private investment in education, relaxing this assumption, i.e., allowing parents to invest in children's education, will not change the results. The following corollary shows that private investment in education cannot coexist with publicly provided education that is made available through the political process of voting.

Corollary 1 In the political economy of public education, private investment in education is optimally driven to the zero corner when a politically determined public education is in place.

\subsection{Political Economy of Pension}

We now proceed to consider an economy that politically implements only a social security program. Just as in a laissez-faire economy discussed in section 2, a proportional tax $\tau_{t}$ is imposed at period $t$ on the wage income earned by a generation $-t$ agent. The total tax revenue is then collected and used up to provide PAYG social security $b_{t}$ to the old generation at $t$. The government's budget balance requirement for this program ensures $b_{t}=\tau_{t} w_{t} h_{t}$. The social

\footnotetext{
${ }^{13}$ If we consider non-constant population, then the equilibrium education tax is still independent of the states of the economy, but it will depend on the population growth rate and therefore will change over time. In particular, if $n_{t}$ is the population growth rate at period $t$, the equilibrium tax rates will turn out to be

$$
\begin{aligned}
\theta_{t}^{G} & \equiv \beta \delta \frac{1-\alpha+\phi\left(1+n_{t+1}\right)}{\Omega_{t+1}}, \tau_{t}^{P}=\frac{\omega-\alpha\left(1+n_{t}\right) \Omega_{t+1} /(1-\alpha)}{\omega+\left(1+n_{t}\right) \Omega_{t+1}} \\
\theta_{t}^{X} & =\frac{\beta \delta\left[1-\alpha+\phi\left(1+n_{t+1}\right)\right] /(1-\alpha)}{\omega+n_{t}(1+\alpha \delta)+\Omega_{t+1}}, \tau_{t}^{X}=\frac{\omega-\alpha\left[n_{t}(1+\alpha \delta)+\Omega_{t+1}\right] /(1-\alpha)}{\omega+n_{t}(1+\alpha \delta)+\Omega_{t+1}}
\end{aligned}
$$

where $\Omega_{t+1}=1+\alpha \delta+\beta \delta(1-\alpha)+\beta \delta \phi\left(1+n_{t+1}\right)$.

${ }^{14} \mathrm{~A}$ point to note here is that the political economy relies on the welfare maximizing tax rates. This paper does not deal with the issue of growth maximizing tax rates and it can be checked that welfare and growth maximizing tax rates are generally not same. For example, in this particular case, the growth maximizing education tax rate is $1-\alpha$, which is different from $\theta^{G}$.
} 
security tax rate, $\tau_{t}$, is determined in the same political setting as in section 3.1. Given the factor prices, human capital production technology, the social security program and the budget constraints, a generation $-t$ agent's optimization problem now involves maximizing (1) subject to $c_{t}^{m}=\left(1-\tau_{t}\right) w_{t} h_{t}-s_{t}-e_{t}$ and $c_{t+1}^{o}=R_{t+1} s_{t}+b_{t+1}$. Thus given $\tau_{t}$, the first order conditions with respect to $\left(e_{t}, s_{t}\right)$ are given by

$$
u^{\prime}\left[\left(1-\tau_{t}\right) w_{t} h_{t}-s_{t}^{P}-e_{t}^{P}\right]=\delta \phi u^{\prime}\left(h_{t+1}\right) \frac{\partial h_{t+1}}{\partial e_{t}}
$$

and

$$
u^{\prime}\left[\left(1-\tau_{t}\right) w_{t} h_{t}-s_{t}^{P}-e_{t}^{P}\right]=\delta R_{t+1} u^{\prime}\left(R_{t+1} s_{t}^{P}+b_{t+1}\right) .
$$

Solving the above two simultaneously results in the following equilibrium values of $e_{t}^{P}$ and $s_{t}^{P}$ :

$$
e_{t}^{P}=\beta \delta \phi \frac{\left(1-\tau_{t}\right) w_{t} h_{t}+b_{t+1} / R_{t+1}}{1+\delta+\beta \delta \phi}
$$

and

$$
s_{t}^{P}=\frac{\delta\left(1-\tau_{t}\right) w_{t} h_{t}-(1+\beta \delta \phi) b_{t+1} / R_{t+1}}{1+\delta+\beta \delta \phi} .
$$

As in section 3.1, we next consider the welfare effects of the social security tax $\tau_{t}$ on the middle-aged workers and the old retirees. Differentiating the utility of the old with respect to $\tau_{t}$ yields $\partial V_{t}^{o} / \partial \tau_{t}=u^{\prime}\left(c_{t}^{o}\right) w_{t} h_{t}>0$. Since the old benefit from the social security program without bearing any cost, it is evident that they always prefer a tax rate that is as high as possible. Compared to the political economy of public education, in which the utility of the present old is not at all affected by the tax rate on education, either directly or through the general equilibrium effect, here in the presence of backward intergenerational goods, e.g., PAYG social security, the old will have a role to play in the political decision making process.

By using the government's balanced budget condition $b_{t}=\tau_{t} w_{t} h_{t}$, market clearing condition $k_{t+1}=s_{t}$, and the factor prices, the welfare effect of social security tax $\tau_{t}$ on a generation $-t$ agent is ${ }^{15}$

$$
\frac{\partial V_{t}^{m}}{\partial \tau_{t}}=\underbrace{-u^{\prime}\left(c_{t}^{m}\right) w_{t} h_{t}}_{\mathcal{E}}+\delta u^{\prime}\left(c_{t+1}^{o}\right)(\underbrace{\tau_{t+1} w_{t+1} \frac{\partial h_{t+1}}{\partial \tau_{t}}}_{\mathcal{F}}+\underbrace{w_{t+1} h_{t+1} \frac{\partial \tau_{t+1}}{\partial \tau_{t}}}_{\mathcal{G}}+\mathcal{H})
$$

\footnotetext{
${ }^{15}$ By the envelope theorem, the effect of $\tau_{t}^{P}$ on the savings and education investment of the middle aged cancels out.
} 
where

$$
\mathcal{H}=s_{t}^{P}(\underbrace{\frac{\partial R_{t+1}}{\partial k_{t+1}} \frac{\partial k_{t+1}}{\partial \tau_{t}}}_{\mathcal{H}^{1}}+\underbrace{\frac{\partial R_{t+1}}{\partial h_{t+1}} \frac{\partial h_{t+1}}{\partial \tau_{t}}}_{\mathcal{H}^{2}})+\tau_{t+1} h_{t+1}(\underbrace{\frac{\partial w_{t+1}}{\partial k_{t+1}} \frac{\partial k_{t+1}}{\partial \tau_{t}}}_{\mathcal{H}^{3}}+\underbrace{\frac{\partial w_{t+1}}{\partial h_{t+1}} \frac{\partial h_{t+1}}{\partial \tau_{t}}}_{\mathcal{H}^{4}}) .
$$

The first negative term $\mathcal{E}$ reflects the direct cost of social security contributions. The second term $\mathcal{F}$ captures the effect of social security tax which reduces the level of education of the next generation and consequently the transfer benefits that the present middle aged generation receives when old. Explicitly, this effect of social security tax on the level of education acquired by the next generation can be derived from the expression of equilibrium $e_{t}^{P}$ (equation (9)) and also by using the equilibrium prices as follows:

$$
\frac{\partial h_{t+1}}{\partial \tau_{t}}=\frac{\beta h_{t+1}}{\left(1-\tau_{t}\right) w_{t} h_{t}+b_{t+1} / R_{t+1}} \underbrace{\left\{-w_{t} h_{t}+\frac{\partial\left(\tau_{t+1} w_{t+1} h_{t+1} / R_{t+1}\right)}{\partial \tau_{t}}\right\}}_{\mathcal{I}} .
$$

According to (9), the investment decision of private education completely relies on parents' life-time income, and the social security affects the human capital accumulation by changing the present value of parents' life-time income $\left(1-\tau_{t}\right) w_{t} h_{t}+b_{t+1} / R_{t+1}$ through two different channels: 1) by directly reducing the wage income of the middle aged, it crowds out parental investment in children's education and 2) by indirectly changing the equilibrium factor prices and the future social security program, it changes the present value of future social security benefit $b_{t+1} / R_{t+1}$. Note that in equilibrium, $b_{t+1} / R_{t+1}=\tau_{t+1} w_{t+1} h_{t+1} / R_{t+1}=(1-\alpha) \tau_{t+1} k_{t+1} / \alpha$ and therefore $\mathcal{I}=-w_{t} h_{t}+(1-\alpha) / \alpha \partial\left(\tau_{t+1} k_{t+1}\right) / \partial \tau_{t}$. As will be shown below, in equilibrium $\tau_{t+1}$ is independent of $\tau_{t}$. This together with the fact that $\partial k_{t+1} / \partial \tau_{t}<0$, results in the negativity of the second indirect effect. As a result, $\mathcal{I}$ as well as $\partial h_{t+1} / \partial \tau_{t}<0$ is negative. The third term $\mathcal{G}$ captures the effect of the current tax choice on the future tax outcome and will be cancelled out if the equilibrium tax rate is independent of the states of the economy.

The last term $\mathcal{H}$ reflects the general equilibrium effect of social security tax through the channel of physical and human capital on the factor prices. By shifting income from the middle-aged to the old, the PAYG social security reduces savings as well as the physical capital investment. The effect of social security tax on the physical capital investment is thus negative i.e., $\partial k_{t+1} / \partial \tau_{t}<0$. Here the movements of capital in terms of backward intergenerational goods not only decreases the level of physical capital in the future, thus increasing the rate of interest, but also decreases the level of investment in human capital for the next generation, consequently reducing human capital in the future. This in turn leads to an opposite effect (compared to physical capital) on the rate of interest. We see a similar thing happening with the other factor price, namely wages. While wages fall owing to the fact that there is a loss in 
physical capital due to backward transfer, we will also expect the price of human capital to be augmented since human capital also goes down in the future. Thus, unlike the previous case of political economy of public education, there is always a tension between the two opposite effects of two types of capital on the factor prices. Therefore $\mathcal{H}^{1}$ and $\mathcal{H}^{4}$ are positive and $\mathcal{H}^{2}$ and $\mathcal{H}^{3}$ are negative, with the result that the sign of the aggregate general equilibrium effect of the social security tax, $\mathcal{H}$, is ambiguous. Indeed this particular result has support from the existing literature. As emphasized by, for e.g., Boldrin and Rustichini (2000) and Gonzalez-Eiras and Niepelt (2008), the general equilibrium effect is very crucial in sustaining the social security program in equilibrium. Our analysis in a different framework, in fact, shows that the general equilibrium effect is also possible to help PAYG program sustainable.

In equilibrium, as usual, political candidates who maximize their respective vote shares propose the same policy platform and maximize the combination of the welfare of all voters, which is given by $\mathcal{W}\left(\mathcal{S}^{t} ; \tau_{t}\right)=\omega V_{t}^{o}\left(\mathcal{S}^{t} ; \tau_{t}\right)+V_{t}^{m}\left(\mathcal{S}^{t} ; \tau_{t}\right)$. First by substituting the factor prices, private optimal savings and education investment (expressions (10), (9)), and imposing the equilibrium condition $k_{t+1}=s_{t}$ in $\mathcal{W}\left(\mathcal{S}^{t} ; \tau_{t}\right)$, and then by omitting the terms independent of policy parameter $\tau_{t}$, the political objective function $\mathcal{W}\left(\mathcal{S}^{t} ; \tau_{t}\right)$ reduces to

$$
\mathcal{W}\left(\mathcal{S}^{t} ; \tau_{t}\right) \simeq \omega \ln \left[\alpha+\tau_{t}(1-\alpha)\right]+\Omega \ln \left(1-\tau_{t}\right)
$$

Following Gonzalez-Eiras and Niepelt (2008), we here make a conjecture that future equilibrium policy $\tau_{t+1}$ is independent of current political choice of $\tau_{t}$, which will be verified to be indeed the case. Solving the first order condition of the probabilistic-voting problem, i.e., by setting $\partial \mathcal{W}\left(\mathcal{S}^{t} ; \tau_{t}\right) / \partial \tau_{t}=0$, we have

Lemma 3 In a political economy with PAYG social security determined in a probabilistic-voting setting, there exists an unique social security tax rate $\tau^{P}$ under MPE and is given by

$$
\tau^{P}=\frac{\omega-\alpha \Omega /(1-\alpha)}{\omega+\Omega}<1 \forall t .
$$

Under logarithmic utility, the equilibrium social security tax is independent of the states of the economy, verifying the conjecture we made above. ${ }^{16}$ By using the government's balanced budget condition $b_{t}=\tau_{t} w_{t} h_{t}$, and the market clearing condition $k_{t+1}=s_{t}$, the dynamical system of the economy can be written as $k_{t+1}^{P}=\alpha \delta A k_{t}^{\alpha} h_{t}^{1-\alpha} /[\alpha \delta+\omega(1+\alpha \delta+\beta \delta \phi) / \Omega]$ and $h_{t+1}^{P}=B k_{t}^{\alpha \beta} h_{t}^{1-\alpha \beta}\{A \omega \beta \delta \phi /[(\alpha \delta+\omega(1+\alpha \delta+\beta \delta \phi) / \Omega)(\omega+\Omega)]\}^{\beta}$. Given $k_{0}$ and $h_{0}$, all dynamic, competitive equilibria are characterized by sequences of $\left\{k_{t}^{P}, h_{t}^{P}\right\}$ that satisfy the two

\footnotetext{
${ }^{16} \mathrm{~A}$ point to note here is that our analysis can generate the results in Gonzalez-Eiras and Niepelt (2008) as a special case. Gonzalez-Eiras and Niepelt (2008) uses a two-period overlapping generations model that features a positive population growth $n_{t}$ in order to study the pension tax. If we impose $\beta=0$ to shut out the education investment in our model, the equilibrium pension tax is $\tau^{P}=[\omega-\alpha(1+\alpha \delta) /(1-\alpha)] /(\omega+1+\alpha \delta)$, which is exactly equal to the result of Gonzalez-Eiras and Niepelt (2008) with $n_{t}=1$.
} 
equilibrium paths as expressed above.

\subsection{Political Economy of Two-Armed Intergenerational Transfers}

While in the previous two subsections we deal with only one fiscal instrument at a time, this subsection deals with the situation when both the forward and backward intergenerational goods are present, that is, when the economy is two-armed. In this setting, the government has two public programs and the budget balance conditions require $e_{t}=\theta_{t} w_{t} h_{t}$ and $b_{t}=\tau_{t} w_{t} h_{t}$ where $\theta_{t}$ and $\tau_{t}$ are the education and social security tax rate respectively imposed on the wage income of the middle-aged workers. Given the tax rates, an agent maximizes (1) subject to $c_{t}^{m}=\left(1-\theta_{t}-\tau_{t}\right) w_{t} h_{t}-s_{t}$ and $c_{t+1}^{o}=R_{t+1} s_{t}+b_{t+1} \cdot{ }^{17}$ Solving the generation- $t$ agent's optimization problem, we obtain

$$
s_{t}^{X}=\frac{\left(1-\theta_{t}-\tau_{t}\right) \delta w_{t} h_{t}-b_{t+1} / R_{t+1}}{1+\delta}
$$

We will now consider the welfare effects of social security tax and education tax on the middle-aged workers and the old retirees. It can be verified that for the old, (given $\tau_{t}$ ) the welfare effect of education tax, i.e., $\partial V_{t}^{o} / \partial \theta_{t}=0$, and (given $\theta_{t}$ ) the welfare effect of social security tax, i.e., $\partial V_{t}^{o} / \partial \tau_{t}=u^{\prime}\left(c_{t}^{o}\right) w_{t} h_{t}$, remain same as in the previous cases. Since neither of the two public policies can modify the current states of the economy, there can only be the direct effect of taxation on the old. Further, it can be verified that (given $\theta_{t}$ ) the welfare effect of social security tax on the middle-aged is the same as in the case (see equation 11) in which only the social security policy is present; however, (given $\tau_{t}$ ) the welfare effect of education tax changes to

$$
\frac{\partial V_{t}^{m}}{\partial \theta_{t}}=\mathcal{J}+\underbrace{\delta u^{\prime}\left(c_{t+1}^{o}\right) \frac{\partial\left(\tau_{t+1} w_{t+1} h_{t+1}\right)}{\partial \theta_{t}}}_{\mathcal{K}}
$$

where $\mathcal{J}$ denotes the right hand side of (8). Further, when a social security tax accompanies an education tax, the term $\mathcal{K}$ represents an extra welfare effect of education tax on the middle-aged where

$$
\frac{\partial\left(\tau_{t+1} w_{t+1} h_{t+1}\right)}{\partial \theta_{t}}=\tau_{t+1} w_{t+1} \frac{\partial h_{t+1}}{\partial \theta_{t}}+\tau_{t+1} h_{t+1}\left(\frac{\partial w_{t+1}}{\partial k_{t+1}} \frac{\partial k_{t+1}}{\partial \theta_{t}}+\frac{\partial w_{t+1}}{\partial h_{t+1}} \frac{\partial h_{t+1}}{\partial \theta_{t}}\right)+w_{t+1} h_{t+1} \frac{\partial \tau_{t+1}}{\partial \theta_{t}}
$$

As we can see $\mathcal{K}$ captures the welfare effect of education tax that the agents pay in the middle age on the social security benefit that they will receive in the future when old. As discussed previously, the general equilibrium effects of public education are $\partial k_{t+1} / \partial \theta_{t}<0$ and $\partial h_{t+1} / \partial \theta_{t}>0$,

\footnotetext{
${ }^{17}$ In order to make the model consistent with that in subsection 3.1 , we here also exclude the private investment in education from agent's choice set.
} 
along with $\partial w_{t+1} / \partial k_{t+1}>0$ and $\partial w_{t+1} / \partial h_{t+1}<0$. Given the sign of these effects along with the fact that $\partial \tau_{t+1} / \partial \theta_{t}=0$ (as will be shown below), the sign of $\mathcal{K}$ becomes indeterminate.

Note that in the economy where only education policy is in existence and is politically determined, the middle aged agents support the education tax because they can gain from the investment in public education through parental altruism as well as from the positive general equilibrium effect of education tax on the interest rate. Our analysis confirms that in the presence of social security, the effect of education tax is not necessarily positive. The result explains that introducing PAYG may not increase the benefits from public education monotonically. This is in contrast to the existing results that appear in Pogue and Sgontz (1977), Becker and Murphy (1988) and Rangel (2003), where the authors based their study in a partial equilibrium framework. They argue that since the enhanced human capital of the next generation can increase the future social security benefit, the presence of social security would increase the incentive of the middle-aged to invest in public education. In fact, in (15), if we drop all the terms that are related to the general equilibrium effects, that is, except the first term, we can verify that an increase in education will have beneficial effect on the generosity of social security when old, given $\partial h_{t+1} / \partial \theta_{t}>0$. This is in the same spirit as the key result of the above three papers mentioned above. However, the result changes once the general equilibrium effects are taken into account and this somewhat supports the findings by Soares (2006) and very recently by Kaganovich and Zilcha (2012). ${ }^{18}$

In equilibrium, the objective function for the political candidates becomes $\mathcal{W}\left(\mathcal{S}^{t} ; \theta_{t}, \tau_{t}\right)=$ $\omega V_{t}^{o}\left(\mathcal{S}^{t} ; \theta_{t}, \tau_{t}\right)+V_{t}^{m}\left(\mathcal{S}^{t} ; \theta_{t}, \tau_{t}\right)$. By substituting the agent's optimal savings (13), government's balanced budgets for the two programs, factor prices and equilibrium market clearing condition into $\mathcal{W}\left(\mathcal{S}^{t} ; \theta_{t}, \tau_{t}\right)$, and then dropping the irrelevant terms, the political objective function $\mathcal{W}\left(\mathcal{S}^{t} ; \theta_{t}, \tau_{t}\right)$ reduces to

$$
\mathcal{W}\left(\mathcal{S}^{t} ; \theta_{t}, \tau_{t}\right) \simeq \omega \ln \left[\alpha+\tau_{t}(1-\alpha)\right]+(1+\alpha \delta) \ln \left(1-\theta_{t}-\tau_{t}\right)+\beta \delta(1-\alpha+\phi) \ln \left(\theta_{t}\right)
$$

The optimal tax rates are simultaneously determined in a repeated probabilistic voting. We solve for the two tax rates by solving the two first order conditions $\partial \mathcal{W}\left(\mathcal{S}^{t} ; \theta_{t}, \tau_{t}\right) / \partial \theta_{t}=0$ and $\partial \mathcal{W}\left(\mathcal{S}^{t} ; \theta_{t}, \tau_{t}\right) / \partial \tau_{t}=0$ simultaneously. As before, we make the conjecture that the future equilibrium policy $\tau_{t+1}$ is independent of current political choice of $\theta_{t}$ and $\tau_{t}$ and will verify that it is indeed the case. Solving the MPE for this probabilistic-voting problem gives us the following lemma.

Lemma 4 In a political economy with public education and PAYG social security determined in a probabilistic-voting setting, there exists a unique set of instruments $\left(\theta^{X}, \tau^{X}\right)$ under MPE

\footnotetext{
${ }^{18}$ Soares (2003) shows that public funding in education may well be a consequence of a purely selfish behavior of agents. It does not have to be supported as an instrument of altruism. It can instead be accounted for by the existence of borrowing constraints and the presence of factor complementarity.
} 
where $\tau^{X}=\tau^{P}$ and

$$
\theta^{X}=\frac{\beta \delta(1-\alpha+\phi) /(1-\alpha)}{\omega+\Omega} \in(0,1) \forall t
$$

Under logarithmic utility, the equilibrium social security tax is independent of the states of the economy, verifying the conjecture. Under this repeated stage game, every subgame thus has an unique Nash equilibrium. This in fact confirms that this is the unique Nash equilibrium for the entire game. Thus the short run taxes that have been obtained simultaneously at each period $t$, are valid not only for each $t$ but also valid for the long run. Using these two equilibrium tax rates, the equilibrium market clearing condition and the budget constraints, the two-dimensional first-order dynamical system of the economy can be written as $k_{t+1}^{X}=$ $\alpha \delta(1+\alpha \delta) A k_{t}^{\alpha} h_{t}^{1-\alpha} /[\omega+\alpha \delta(\omega+\Omega)]$ and $h_{t+1}^{X}=B[A \beta \delta(1-\alpha+\phi) /(\omega+\Omega)]^{\beta} k_{t}^{\alpha \beta} h_{t}^{1-\alpha \beta}$. Given $k_{0}$ and $h_{0}$, all dynamic, competitive equilibria are characterized by sequences of $\left\{k_{t}^{X}, h_{t}^{X}\right\}$ that satisfy the above two equilibrium paths. Finally we end the section by presenting the steady state equilibrium for the above three political economies.

Lemma 5 In each of the three political economies presented above, there exists a unique steady state with balanced growth where the human and physical capital grow at a same constant rate.

\section{Policy Consequences}

Economic growth is mainly driven by the accumulation of physical capital and human capital. As two of the largest public transfer programs in most economies, public education and social security exert significant influence on the accumulation of these two types of capital and thus on the long run growth. In this section, we are particularly interested in how these two public programs exert that influence in a political economy. When the government is short-lived and commitment issue is subtle, the outcome in the period-wise voting represents the true wishes of an economy in terms of the allocation of resources. Moreover, as mentioned in the introduction, there is a wide variety of studies on these two transfers, but most of them are in isolation from the other. The results could be misleading if we ignore the presence of the other policy due to the possible interaction between the two intergenerational transfers in a political economy. The unified framework that we present here allows us to compare ${ }^{19}$ the results of different treatments of these two intergenerational transfers, something that have been done only partially in previous studies. In this process we end up with some interesting results that are presented below.

We focus on two important aspects of intergenerational transfers when there are conflicts of interests among generations. First we study the effects of politically establishing these two

\footnotetext{
${ }^{19}$ Whenever a comparison is made in our analysis, we naturally assume that the state variables at period $t$ are same for all the cases. Changes appear from $t+1$ and the crucial variables are represented with the superscripts then.
} 
large public programs both individually as well as jointly. Second, we investigate the role that is played by the relative influence of the old in the political process when both programs are present. This is more important because developed and developing countries are experiencing significant demographic change where the proportion of old people in the population is steadily increasing.

We first examine the case of public education in a political economy. In all that follows, we particularly concentrate on the effects of the intergenerational transfer policy on the short run accumulation of both human and physical capital as well as their growth in the long run.

Proposition 1 (1) Politically establishing a public education program always increases (depresses) human (physical) capital accumulation, and therefore can boost the long run growth when the production technology is intensive in human capital, i.e., $\alpha$ is small. However,

(2) the increase in human capital 'does not' necessarily guarantee a generous social security in the future.

Since establishing a public education program has no economic gain to the current old retirees, evidently it is the middle aged agents who decide the education investment in the political process. As a voter, when deciding on investment in education, besides the altruism effect, the rational middle-aged agent also takes into account the afore-discussed (positive) general equilibrium effect of education investment which she is unaware of as a consumer. As a consequence, the education investment optimally chosen in the political process is higher than the private education investment. If we disregard the general equilibrium effect of education investment in the voting process, i.e., $\mathcal{C}$ and $\mathcal{D}$ in (8), the investment in public education would be exactly equal to the investment in private education, adjusted to per unit tax. Implementing public education however reduces physical capital accumulation as expected, because the increase in education investment expands the tax burden of the middle aged, which would in turn crowds out their savings. Since public education generates countervailing effects on the accumulation of physical capital and human capital, if the production function is human capital intensive, i.e., $\alpha$ is small, then the human capital enhancement effect dominates so that public education ensures higher growth in the long run.

It has been argued in the literature that by suitably extending the forward arm, backward arm that is social security can be stable and welfare improving. An implied view is that if today's middle aged generation increases their investment in the young generation's education, the productivity of future working population can be amplified, and therefore they can enjoy higher social security benefit when old. However, Proposition 1 shows that, although the public education program provides more funding for investment in the next generation's education than private parental investment, if PAYG social security is politically determined, the increase in the level of education does not at all guarantee an increase in the social security benefit. Since according to Lemma 4, politically establishing a public education program has completely 
no impact on the equilibrium social security tax rate, i.e., $\tau^{X}=\tau^{P}$, we have to admit that politically establishing public education program may increase the current value of future social security benefit, $\tau_{t+1} w_{t+1} h_{t+1}$, due to the enlarged human capital $h_{t+1}$. However it is not at all guaranteed since in the meanwhile the future wage rate $w_{t+1}$ also falls due to the increase in $h_{t+1}$, as well as the decrease in $k_{t+1}$. Further, the changes in the levels of both human and physical capital also drives up the future interest rate $R_{t+1}$, which may well reduce the present value of future social security benefit. More specifically, in our logarithmic setup, the present value of future social security benefit, $\tau_{t+1} w_{t+1} h_{t+1} / R_{t+1}$, in equilibrium equals to $\tau_{t+1}(1-\alpha) k_{t+1} / \alpha$, which in fact decreases.

We next consider the policy implication of politically establishing a PAYG social security program. As is standard in the literature, implementing the PAYG social security always depresses physical capital accumulation, no matter whether the education investment is privately or publicly funded. However regarding the policy implications of social security on human capital accumulation, the funding source of education investment matters.

Proposition 2 (1) In an economy that already has an established public education program, politically establishing a PAYG social security always depresses the human capital accumulation.

(2) In a laissez-faire economy, politically establishing a PAYG social security, independently or together with a public education program, can increase human capital accumulation if and only if the political influence of the old is small (less than a particular threshold value of $\omega$ ) so that the size of the social security program is limited. ${ }^{20} A$ substantially thick social security scheme spoils this mutual benefit.

The first result of Proposition 2 reflects the conflicts of interests among generations in the public policy decision making. As mentioned before, the old have no interest in establishing a public education program and it is the middle-aged who make this investment decision during the political process. As voters, the middle-aged need to balance the marginal cost and marginal benefit of this investment. Note that the public education investment reduces the family budget available for the middle-age consumption as well as physical capital investment and hence its marginal cost is the aggregate value of the marginal utility of the forgone consumption during the middle and old age. Since PAYG social security taxation further reduces the family budget of the middle aged, due to the concavity of the utility function, the marginal cost for the same level of public education investment would be higher than before. On the other hand, the benefit of middle-age education investment is a higher level of human capital in the future. In particular, the future old-age consumption in equilibrium is $\left[\alpha+(1-\alpha) \tau_{t+1}\right] A k_{t+1}^{\alpha} h_{t+1}^{1-\alpha}$, and under logarithmic utility, the middle-age contribution to the social security has no effect on the value of the marginal increase of future human capital. As a consequence, politically

\footnotetext{
${ }^{20}$ Since $\omega$ is the key to the intergenerational conflicts or cooperation, we use the parameter $\omega$ when comparing. See the proof in the appendix for the two threshold values of $\omega$.
} 
establishing a PAYG social security increases the marginal cost of public education investment without making any contribution to its marginal benefit. If we compare the two equations $\partial \mathcal{W}\left(\mathcal{S}^{t} ; \theta_{t}\right) / \partial \theta_{t}=0$ and $\partial \mathcal{W}\left(\mathcal{S}^{t} ; \theta_{t}, \tau_{t}\right) / \partial \theta_{t}=0$, which are shown respectively in the proof of Lemma 2 and Lemma 4 , it can be seen that the marginal benefit part in these two first order conditions are exactly same while the marginal cost part differs by the term $\tau_{t}$.

Evidently when the public education program is already present, introducing a PAYG social security program would compete with public education for government revenue and therefore crowds out the public funding for the public education program, depressing the human capital accumulation. Moreover, higher political weight of the old yields higher social security tax rate, which in turn would crowd out more public investment in education. Since politically establishing a PAYG social security program adversely affects both physical and human capital accumulation, the long run growth would definitely be depressed in this case. It needs to be stressed that because public education has been in existence in the history for several hundred years, and the PAYG social security came into the picture only in the twentieth century, the result has a very important implication for the real economies. It suggests that the public education investment and long run growth would generally be hurt if an economy decides to implement PAYG social security through a voting process.

Proposition 2, however, also shows that when education is privately funded in the laissezfaire economy, politically establishing a PAYG social security program can help stimulate investment in education, generating more human capital accumulation than the laissez-faire under a no commitment voting equilibrium. We show that when political weight of the old is relatively small, the political candidate would choose a mild (limited) social security at the equilibrium when the education regime is private. Thus a political economy that consists of high education and limited social security can well be an equilibrium outcome. However, a heavy relative influence of the old demands a substantially high social security benefit which spoils the benefits of coexisting education and social security and in fact leads to an education level that is less than the laissez-faire. In this part 2 of Proposition 2, we present two possible cases. The first situation is one where the education regime is private and social security is chosen by voting. The second case represents a situation when initially the education regime is private but a package comprising of public education and public social security is implemented through voting. The later one can be considered as a political economy version of Boldrin and Montes (2005) where public education - public social security are implemented as a package.

Let us explain the results under part (2) of the Proposition 2 when social security is infused separately. The parents completely rely on their own income to make the private education investment decision and would increase the investment in children's education if and only if the present value of the life-cycle income increases. When education is privately funded, for a middle aged agent, social security program reduces the current income by $\tau_{t} w_{t} h_{t}$ but increases her future income by $\tau_{t+1} w_{t+1} h_{t+1}$. Thus whether politically establishing a PAYG social security 
program will increase the education investment completely depends on whether the benefits from future social security can dominate the tax loss at middle age, i.e., $\tau_{t+1} w_{t+1} h_{t+1} / R_{t+1}>$ $\tau_{t} w_{t} h_{t}$, or equivalently $w_{t+1} h_{t+1} / R_{t+1}>w_{t} h_{t}$. Here both $w_{t}$ and $h_{t}$ are predetermined but $w_{t+1}, h_{t+1}$ and $R_{t+1}$ would be all affected by the newly established social security program. As previously mentioned, establishing a PAYG social security program always reduces the physical capital accumulation, which would in turn increase $R_{t+1}$ and depress $w_{t+1}$, but when the relative political power of the old retirees $\omega$ is small so that the public social security program is limited, the physical capital accumulation is less adversely affected and could still be high. ${ }^{21}$ In this case, if leaving $h_{t+1}$ unchanged, the future interest rate $R_{t+1}$ would be relatively low and the future wage rate $w_{t+1}$ would be relatively high, both of which would in turn contribute to the higher present value of $w_{t+1} h_{t+1} / R_{t+1}$. If $\omega$ is sufficiently small, $w_{t+1} h_{t+1} / R_{t+1}$ could be high enough to overcompensate the loss in income $w_{t} h_{t}$ at present and thus the present value of life-cycle income may increase. An enhanced life cycle income of the parents then guarantees higher investment in children's education at the equilibrium. The opposite happens when the political power of the old is sufficiently high so that the PAYG social security program is large. ${ }^{22}$

The result that we present in the second case under part (2) is also very intuitive. We have shown in Proposition 1 that as public education program is established in an economy, it always increases the human capital investment no matter whether the PAYG social security is present or not. But on the other hand, politically establishing PAYG social security program, as shown in the part (1) of Proposition 2, would discourage public education investment. The human capital investment thus can be enhanced (compared to the laissez-faire private human capital investment) if and only if the PAYG social security is limited so that its effect on public education investment is also limited. This particular finding is related to some of the influential studies in the literature. In fact this results can be seen as a political economy version of the work of Boldrin and Montes (2005) which rationalize the simultaneous establishment of the two programs purely on efficiency grounds. Their influential study confirms that when a market for borrowing funds for education is absent, a properly designed education - social security package is capable of generating the complete market allocation. In our political economy setup, if we focus on the effects of these transfer policies on the long-run growth and verify whether simultaneous establishment of these two-armed intergenerational transfers are justifiable, the answer depends on the distribution of the political power. Simultaneous subsidy on education and social security would hurt the long-run growth of the economy when influence of the old is

\footnotetext{
${ }^{21}$ Note that the equilibrium social security $\operatorname{tax} \tau^{P}$ is monotonically increasing in the relative political power of the old retirees $\omega$. In addition, it can easily be verified that there exists a weight $\omega(\widehat{\omega}$ in the proof of the above proposition) at which $\tau^{P}$ equals to zero. Hence the equilibrium social security tax is positive if and only if $\omega \geq \widehat{\omega}$, and we are focusing only on the situation when pension tax rate is positive.

${ }^{22}$ Using 1995 and 2002 household survey data and difference in difference model, Sun and Yi (2014) find that the 1997 social security reform in China, which cut down the replacement rate of employee' social security benefit from $80 \%$ to $58.5 \%$, significantly increased the household education investment.
} 
very high so that the social security program is very substantial. It may benefit the long-run growth of the economy when the relative influence of the old is limited so that human capital accumulation is increased and the production technology is intensive in human capital, i.e., $\alpha$ is small. One more significant result in this literature is Rangel (2003) where an education - pension package is supported by trigger strategy argument which demands a continuation surplus. Thus a heavy backward payments incentivise investment in the forward arm. Our model points out that a problem that a sufficiently heavy backward transfer is not cost less - it may reduce the generosity of the forward arm and therefore, a sufficiently heavy social security along with education subsidy as a package may end up with a lower level of education and upset the mutual benefit. Thus a heavy influence of the old in the political process may reduce the investment in education.

In both the two situations mentioned in part (2) of Proposition 2, the overall message is that when higher level of education is concerned, there exists a situation where a mild social security scheme is better compared to a situation with no social security. This result indicates a positive side of the existence of public social security where a mutual benefit of higher level of education (compared to laissez-faire) and a limited social security can very well coexist at the cost of reduced physical capital. However, when the influence of the old steadily increases and it becomes substantial, it demands thick social security benefits which may hurt education and results in an education level that is lower than the level that the laissez-faire guarantees.

\section{Conclusion}

This study reveals some important results which make our understanding of the effects of the intergenerational transfer policies clear. In this paper, whenever we consider a policy, we allow the economy to endogenously determine its size and therefore all the policies are endogenous. Further, the government is short-lived and they cannot commit to the future policies. Agents on the other hand are subject to intergenerational cooperation and conflict on the issue of intergenerational transfers and as rational voters they internalize all the effects of their policy choices that materialize in their life-span. In this natural setting, we reveal some interesting observations. First we show that when public education is introduced in an economy through a political process of voting, it always reduces the accumulation of physical capital but increases the accumulation of human capital. This is because of a natural assumption that rational agents internalize all the effects of the policy outcomes, including the positive general equilibrium effects that materialize during their life time. This effect is however not realizable in a competitive equilibrium with private funding of education. A stronger result that emerges is that even with an increase in the level of education under the public regime, the generosity of social security may actually fall. This is in contrast to the popular wisdom that changing the 
public funds available for education may ease the payments for PAYG social security in future.

On the other hand, we have been able to show that introducing politically determined public social security most definitely reduces physical capital accumulation. We explain why the presence of social security may not provide sufficient incentive for investment in education, a belief that arises from the present literature. Later we show that when education regime is private, in both the situations when public social security is introduced separately as well as when public education - public social security are implemented as a package, the economy experiences an increase in education but the necessary condition for this is that the public pension program has to be limited. Limited pension in our paper results from a limited political influence of the old in the political process. Thus a mutual benefit of higher level of education (compared to laissez-faire) and a limited social security can well coexist at the cost of reduction in physical capital. Since public social security therefore has two countervailing effects on physical and human capital, securing a higher growth is feasible in our framework too but for that the influence of the old has to be limited. A substantial social security program however is not cost less - it spoils this mutual benefit and results in an education level that is less than the level that laissez-faire generates. Thus, if the question arises whether simultaneous arrangement of these two-armed intergenerational transfers are justifiable for an increase in the long run growth, the answer in our model would depend on the distribution of political power among generations. But human capital will be reduced with certainty if and only if the public education is already present in the economy and the benefits of public education has already been realized.

A nice extension to this study would be to accommodate fertility and longevity since we cannot ignore the effects of these in our framework, especially when the intergenerational equations are changing rapidly. We leave this for our future study. 


\section{References}

[1] ANDERSEN, T. and BHATTACHARYA, J. (2013), "The Intergenerational Welfare State", mimeo, Iowa State University.

[2] BHASKAR, V. (1998), "Informational constraints and the overlapping generations model: folk and anti-folk theorems", Review of Economic Studies, 65, 135-149.

[3] BECKER, G. S. and MURPHY, K. M. (1988), "The Family and the State", Journal of Law and Economics, 31, 1-18.

[4] BISHNU, M. (2013), "Linking Consumption Externalities with Optimal Accumulation of Human and Physical Capital and Intergenerational Transfers", Journal of Economic Theory, 148, 720-742.

[5] BOLDRIN, M. and MONTES, A. (2005), "The Intergenerational State Education and Pensions", Review of Economic Studies, 72, 651-664.

[6] BOLDRIN, M. and RUSTICHINI, A. (2000), "Political Equilibria with Social Security", Review of Economic Dynamics, 3, 41-78.

[7] COOLEY, T.F. and SOARES, J. (1999), "A Positive Theory of Social Security Based on Reputation", Journal of Political Economy 107, 135-160.

[8] CREMER, H., KeSSleR, D. and PeStiEAU, P. (1992), "Intergenerational Transfers within the Family", European Economic Review, 36, 1-16.

[9] DE LA CROIX, D. and DOEPKE, M. (2003), "Inequality and Growth: Why Differential Fertility Matters", American Economic Review, 93, 1091-1113.

[10] DOCQUIER, F., PADDISON, O. and PESTIEAU, P. (2007), "Optimal Accumulation in an Endogenous Growth Setting with Human Capital", Journal of Economic Theory, 134, $361-378$.

[11] FELDSTEIN, M. (2005), "Structural Reform of Social Security", Journal of Economic Perspectives, 19, 33-55.

[12] GLOMM, G. and KAGANOVICH, M. (2003), "Distributional Effects of Public Education in an Economy with Public Pensions", International Economic Review, 44, 917-937.

[13] GLOMM, G. and KAGANOVICH, M. (2008), "Social Security, Public Education and the Growth-Inequality Relationship", European Economic Review, 52, 1009-1034. 
[14] GLOMM, G. and RAVIKUMAR, B. (1992), "Public vs. Private Investment in Human Capital: Endogenous Growth and Income Inequality", Journal of Political Economy, 100, 818-834.

[15] GONZALEZ-EIRAS, M. and NIEPELT, D. (2012), "Ageing, government budgets, retirement, and growth", European Economic Review, 56 (1), 2012, 97-115.

[16] GONZALEZ-EIRAS, M. and NIEPELT, D. (2008), "The Future of Social Security", Journal of Monetary Economics, 55, 197-218.

[17] KAGANOVICH, M. and ZILCHA, I. (1999), "Education, Social Security and Growth", Journal of Public Economics, 71, 289-309.

[18] KAGANOVICH, M. and ZILCHA, I. (2012), "Pay-as-you-go or Funded Social Security? A General Equilibrium Comparison", Journal of Economic Dynamics and Control, 36, 455-467.

[19] LANCIA, F. and RUSSO, A. (2013), "A Dynamic Politico-Economic Model of Intergenerational Contracts", Working Paper No: 1304, Department of Economics, University of Vienna.

[20] LINDBECK, A. and WEIBULL, J. W. (1987), "Balanced-budget Redistribution as the Outcome of Political Competition", Public Choice, 52, 273-297.

[21] LINDERT, P. (1994), "The Rise of Social Spending, 1880-1930", Explorations in Economic History, 31, 1-37.

[22] MULLIGAN, C. and SALA-I-MARTIN, X (1999), "Gerontocracy, Retirement, and Social Security", Working Paper 7117, NBER.

[23] NAITO, K. (2012), "Two-sided Intergenerational Transfer Policy and Economic Development: A Politico-economic Approach", Journal of Economic Dynamics and Control, 36, 1340-1348.

[24] ONO, T. (2013), "Public Education and Social Security: A Political Economy Approach", Discussion paper, Graduate School of Economics and Osaka School of International Public Policy, 13-06.

[25] PECChenino, R. A. and UTENDORF, K. R. (1999), "Social Security, Social welfare and the Aging Population", Journal of Population Economics, 12, 607-623.

[26] POGUE, T. F. and SGONTZ, L. G. (1977), "Social Security and Investment in Human Capital", National Tax Journal, 30,157-169. 
[27] POUTVAARA, P. (2006), "On the Political Economy of Social Security and Public Education", Journal of Population Economics, 19, 345-365.

[28] PRESTON, S. H. (1984), "Children and the Elderly: Divergent Paths for America's Dependents", Demography, 21, 435-457.

[29] RANGEL, A. (2003), "Forward and Backward Intergenerational Goods: Why is Social Security Good for the Environment?", American Economic Review, 93, 813-834.

[30] RICHMAN, H. A. and STAGNER, M. W. (1986), "Children: Treasured Resource or Forgotten Minority", in A. Pifer and L. Bronte (eds.) Our Aging Society: Paradox and Promise (New York: Norton) 161-179.

[31] SOARES, J (2003), "Self-interest and public funding of education", Journal of Public Economics, 87, 703-727.

[32] SOARES, J. (2006), "A Dynamic General Equilibrium Analysis of the Political Economy of Public Education", Journal of Population Economics, 19,367-389.

[33] SONG, Z. (2011), "The Dynamics of Inequality and Social Security in General Equilibrium", Review of Economic Dynamics, 14, 613-635.

[34] SONG, Z., STORESLETTEN, K. and ZILIBOTTI, F. (2012), "Rotten Parents and Disciplined Children: A Politico-Economic Theory of Public Expenditure and Debt", Econometrica, 80, 2785-2803.

[35] SUN, W. and YI, X. (2014), "The Impact of Pension Reform on Households' Education Expenditure: Evidence from China", Working paper (in Chinese), Renming University of China

[36] TABELlinI, G. (2000), "A Positive Theory of Social Security", Scandinavian Journal of Economics, 102, 523-545.

[37] UNITED NATIONS (2013), Department of Economic and Social Affairs, Population Division (2013). World Population Prospects: The 2012 Revision, DVD Edition.

[38] WANG, M. (2013), "Optimal Education Policy under Endogenous Borrowing Constraints", Forthcoming in Economic Theory, DOI 10.1007/s00199-013-0743-5. 


\section{Appendix A}

Proof of Lemma 1. First, using the expressions for the paths of capital accumulation, we have

$$
\frac{k_{t+1}^{L}}{h_{t+1}^{L}}=\frac{[\delta A(1-\alpha)]^{1-\beta}}{B(1+\delta+\beta \delta \phi)^{1-\beta}(\beta \phi)^{\beta}}\left(\frac{k_{t}^{L}}{h_{t}^{L}}\right)^{\alpha-\alpha \beta} .
$$

Then by denoting $\bar{k}_{t+1}^{L} \equiv k_{t+1}^{L} / h_{t+1}^{L}$, we can observe that $\bar{k}_{t+1}^{L}$ is concave in $\bar{k}_{t}^{L}$ with $\lim _{\bar{k}_{t}^{L} \rightarrow 0} \bar{k}_{t+1}^{L}=$ 0 and $\lim _{\bar{k}_{t}^{L} \rightarrow 0} d \bar{k}_{t+1}^{L} / d \bar{k}_{t}^{L}=\infty$. Hence there exists a unique non-trivial steady state value of $\bar{k}^{L}$ which is given by

$$
\bar{k}^{L}=\left\{\frac{[\delta A(1-\alpha)]^{1-\beta}}{B(1+\delta+\beta \delta \phi)^{1-\beta}(\beta \phi)^{\beta}}\right\}^{\frac{1}{1-\alpha(1-\beta)}} .
$$

Further, at the steady state, the growth rate of the human capital is given by

$$
\frac{h_{t+1}^{L}}{h_{t}^{L}}=B\left[\frac{\beta \delta \phi A(1-\alpha)}{1+\delta+\beta \delta \phi}\right]^{\beta}\left(\bar{k}^{L}\right)^{\alpha \beta}=\left\{\frac{B^{1-\alpha}(\beta \phi)^{\beta(1-\alpha)}[\delta A(1-\alpha)]^{\beta}}{(1+\delta+\beta \delta \phi)^{\beta}}\right\}^{\frac{1}{1-\alpha+\alpha \beta}}
$$

which is a constant. It is straightforward to verify that this is also the steady state growth rate for physical capital. Hence the proof.

Proof of Lemma 2. Note that $\theta_{t}^{G}$ is the solution to the first order condition,

$$
\partial \mathcal{W}\left(\mathcal{S}^{t} ; \theta_{t}\right) / \partial \theta_{t}=\frac{\beta \delta(1-\alpha+\phi)}{\theta_{t}^{G}}-\frac{1+\alpha \delta}{1-\theta_{t}^{G}}=0
$$

It is to be noted that $\theta_{t}^{G}=\theta^{G} \forall t$. Further, we can verify $\lim _{\theta_{t} \rightarrow 0} \mathcal{W}\left(\mathcal{S}^{t} ; \theta_{t}\right)=\lim _{\theta_{t} \rightarrow 1} \mathcal{W}\left(\mathcal{S}^{t} ; \theta_{t}\right)=$ $-\infty$, and $\partial^{2} \mathcal{W}\left(\mathcal{S}^{t} ; \theta_{t}\right) / \partial \theta_{t}^{2}<0$ so that the second order sufficient condition is satisfied. Hence the proof.

Proof of Corollary 1. When both the sources of education investment are present, agents maximize (1) subject to $c_{t}^{m}=\left(1-\theta_{t}\right) w_{t} h_{t}-d_{t}-s_{t}, c_{t+1}^{o}=R_{t+1} s_{t}, e_{t}=d_{t}+g_{t}$ and $d_{t} \geq 0$, where $\theta_{t}$ is the education tax rate, $d_{t}$ and $g_{t}$ are the new notations we use for private and public investment in education (we in fact use these notations for this proof only). With the assumption of logarithmic utility and government's budget balance, $g_{t}=\theta_{t} w_{t} h_{t}$, we have

$$
d_{t}^{*}=\left\{\begin{array}{cl}
\frac{\beta \delta \phi-\theta_{t}(1+\delta+\beta \delta \phi)}{1+\delta+\beta \delta \phi} w_{t} h_{t}, & \text { if } \theta_{t}<\frac{\beta \delta \phi}{1+\delta+\beta \delta \phi} \\
0, & \text { if } \theta_{t} \geq \frac{\beta \delta \phi}{1+\delta+\beta \delta \phi}
\end{array}\right.
$$


and

$$
s_{t}^{*}=\left\{\begin{array}{ll}
\frac{\delta w_{t} h_{t}}{1+\delta+\beta \delta \phi}, & \text { if } \theta_{t}<\frac{\beta \delta \phi}{1+\delta+\beta \delta \phi} \\
\frac{\delta\left(1-\theta_{t}\right) w_{t} h_{t}}{1+\delta}, & \text { if } \theta_{t} \geq \frac{\beta \delta \phi}{1+\delta+\beta \delta \phi}
\end{array} .\right.
$$

Next we solve the political equilibrium of education tax rate. First, when $\theta_{t}<\beta \delta \phi /(1+\delta+\beta \delta \phi)$, that is when $d_{t}^{*}>0$, we have

$$
\mathcal{W}\left(\mathcal{S}^{t} ; \theta_{t}\right) \simeq[\beta \delta(1-\alpha)+\beta \delta \phi] \ln \left[\beta \delta \phi-\theta_{t}(\delta+\beta \delta \phi)\right]
$$

The maximum occurs when $\theta_{t}=0$, which guarantees that $d_{t}^{*}>0$ along with $\theta_{t}>0$ cannot coexist. Secondly, when $\theta_{t} \geq \beta \delta \phi /(1+\delta+\beta \delta \phi)$, that is when $d_{t}^{*}=0$, as shown in Lemma 2 , the political equilibrium of education tax rate is $\theta_{t} \equiv \theta^{G}$. We can verify that $\theta^{G}>\beta \delta \phi /(1+\delta+\beta \delta \phi)$ holds since this is equivalent to $(1-\alpha)+\delta[1+\alpha(1-\phi)]>0$ which is true.

Proof of Lemma 3. It is easy to check that $\tau_{t}^{P}$ is the solution to $\partial \mathcal{W}\left(\mathcal{S}^{t} ; \tau_{t}\right) / \partial \tau_{t}=$ 0 . It can also be verified that $\partial^{2} \mathcal{W}\left(\mathcal{S}^{t} ; \tau_{t}\right) / \partial \tau_{t}^{2}<0$ with $\lim _{\tau_{t} \rightarrow 0} \mathcal{W}\left(\mathcal{S}^{t} ; \tau_{t}\right)=\omega \ln \alpha$ and $\lim _{\tau_{t} \rightarrow 1} \mathcal{W}\left(\mathcal{S} ; \tau_{t}\right)=-\infty$. Hence the proof.

Proof of Lemma 4. Since education subsidy and social security tax are simultaneously chosen under a Nash setting, one tax rate is determined assuming the other tax rate is given at the optimum level. Thus, we find out the optimal tax rates $\left(\theta_{t}^{X}, \tau_{t}^{X}\right)$ by simultaneously solving the two first order conditions as follows:

$$
\begin{aligned}
\frac{\partial \mathcal{W}\left(\mathcal{S}^{t} ; \theta_{t}, \tau_{t}\right)}{\partial \tau_{t}} & =\frac{\omega(1-\alpha)}{\alpha+\tau_{t}^{X}(1-\alpha)}-\frac{1+\alpha \delta}{1-\tau_{t}^{X}-\theta_{t}^{X}}=0 \\
\frac{\partial \mathcal{W}\left(\mathcal{S}^{t} ; \theta_{t}, \tau_{t}\right)}{\partial \theta_{t}} & =\frac{\beta \delta(1-\alpha+\phi)}{\theta_{t}^{X}}-\frac{1+\alpha \delta}{1-\tau_{t}^{X}-\theta_{t}^{X}}=0 .
\end{aligned}
$$

It can also be verified that the Hessian of $\mathcal{W}\left(\mathcal{S}^{t} ; \theta_{t}, \tau_{t}\right)$,

$$
\left(\begin{array}{cc}
-\frac{\omega(1-\alpha)^{2}}{\left[\alpha+\tau_{t}^{X}(1-\alpha)\right]^{2}}-\frac{1+\alpha \delta}{\left(1-\theta_{t}^{X}-\tau_{t}^{X}\right)^{2}} & -\frac{1+\alpha \delta}{\left(1-\theta_{t}^{X}-\tau_{t}^{X}\right)^{2}} \\
-\frac{1+\alpha \delta}{\left(1-\theta_{t}^{X}-\tau_{t}^{X}\right)^{2}} & -\frac{1+\alpha \delta}{\left(1-\theta_{t}^{X}-\tau_{t}^{X}\right)^{2}}-\frac{\beta \delta(1-\alpha+\phi)}{\left(\theta_{t}^{X}\right)^{2}}
\end{array}\right)
$$

is negative definite so that the second order sufficient condition is satisfied. Hence the proof.

Proof of Lemma 5. This proof follows the same approach of Proof of Lemma 1. First we can show that for each political economy, there exists a unique non-trivial steady state value 
of $\bar{k}_{t}^{i} \equiv k_{t}^{i} / h_{t}^{i}, i=\{L, P, X\}$, which are respectively given by

$$
\begin{aligned}
& \bar{k}^{G}=\left\{\frac{\delta\left(1-\theta^{G}\right)(1-\alpha) A}{B(1+\delta)\left[\theta^{G}(1-\alpha) A\right]^{\beta}}\right\}^{\frac{1}{1-\alpha+\alpha \beta}}, \\
& \bar{k}^{P}=\left\{\frac{\alpha \delta A(1-\alpha)\left(1-\tau^{P}\right) /\left\{\beta \delta \phi A\left(1-\tau^{P}\right)\left[\alpha+(1-\alpha) \tau^{P}\right]\right\}^{\beta}}{B\left[\alpha(1+\delta+\beta \delta \phi)+(1-\alpha)(1+\beta \delta \phi) \tau^{P}\right]^{1-\beta}}\right\}^{\frac{1}{1-\alpha+\alpha \beta}}, \\
& \bar{k}^{X}=\left\{\frac{A \alpha \delta(1+\alpha \delta)}{B[\omega+\alpha \delta(\omega+\Omega)][A \beta \delta(1-\alpha+\phi) /(\omega+\Omega)]^{\beta}}\right\}^{\frac{1}{1-\alpha+\alpha \beta}} .
\end{aligned}
$$

Further, we can show that for each political economy, at the steady state, both human and physical capital grow at a constant rate and are respectively given by

$$
\begin{aligned}
\frac{h_{t+1}^{G}}{h_{t}^{G}} & =B\left[\theta^{G} A(1-\alpha)\right]^{\beta}\left(\bar{k}^{G}\right)^{\alpha \beta} \\
\frac{h_{t+1}^{P}}{h_{t}^{P}} & =B\left\{\frac{\beta \delta \phi A\left(1-\tau^{P}\right)\left[\alpha+(1-\alpha) \tau^{P}\right]}{\alpha(1+\delta+\beta \delta \phi) /(1-\alpha)+(1+\beta \delta \phi) \tau^{P}}\right\}^{\beta}\left(\bar{k}^{P}\right)^{\alpha \beta} \\
\frac{h_{t+1}^{X}}{h_{t}^{X}} & =B\left(A \beta \delta \frac{1-\alpha+\phi}{\omega+\Omega}\right)^{\beta}\left(\bar{k}^{X}\right)^{\alpha \beta}
\end{aligned}
$$

Hence the proof.

Proof of Proposition 1. The proof of Part 1 relies on (a) the comparison between $\left(e_{t}^{L}, k_{t+1}^{L}\right)$ and $\left(e_{t}^{G}, k_{t+1}^{G}\right)$, and also on (b) the comparison between $\left(e_{t}^{P}, k_{t+1}^{P}\right)$ and $\left(e_{t}^{X}, k_{t+1}^{X}\right)$ element-wise.

(a) We compare between $\left(e_{t}^{L}, k_{t+1}^{L}\right)$ and $\left(e_{t}^{G}, k_{t+1}^{G}\right)$ here. To prove $e_{t}^{G}>e_{t}^{L}$, we need to show that $\theta^{G}>\beta \delta \phi /(1+\delta+\beta \delta \phi)$ and for $k_{t+1}^{G}<k_{t+1}^{L}$, we have to show that $(1+\delta) /(1+\delta+\beta \delta \phi)>$ $\left(1-\theta^{G}\right)$. Using the equilibrium value of $\theta^{G}$, it is straight forward to verify that both the above conditions are equivalent to the condition $\delta \beta(1-\alpha)(1+\delta+\phi \delta) / \Omega>0$, which always holds given our specifications.

Further, the long-run growth rate in the political economy with public education is higher than that in the laissez-faire economy if and only if $\left(h_{t+1}^{G} / h_{t}^{G}\right) /\left(h_{t+1}^{L} / h_{t}^{L}\right)>1$ holds at the steady state. Since $\left(h_{t+1}^{G} / h_{t}^{G}\right) /\left(h_{t+1}^{L} / h_{t}^{L}\right)$ is continuous in $\alpha$, to prove part 2 , it is enough to show that $\left(h_{t+1}^{G} / h_{t}^{G}\right) /\left(h_{t+1}^{L} / h_{t}^{L}\right)>1$ holds when $\alpha=0$. Given $\alpha=0$, some algebra yields $\left(h_{t+1}^{G} / h_{t}^{G}\right) /\left(h_{t+1}^{L} / h_{t}^{L}\right)=\left[\theta^{G}(1+\delta+\beta \delta \phi) /(\beta \delta \phi)\right]^{\beta}$, which is larger than one by directly following the proof presented above.

(b) As mentioned above, here we compare between $\left(e_{t}^{P}, k_{t+1}^{P}\right)$ and $\left(e_{t}^{X}, k_{t+1}^{X}\right)$. Using the equilibrium factor prices, government budget and the expression for $k_{t+1}^{P}$, some tedious algebra 
yields the equilibrium investment in education

$$
e_{t}^{P}=\frac{\omega \beta \delta \phi \Omega}{(\omega+\Omega)[\alpha \delta \Omega+\omega(1+\alpha \delta+\beta \delta \phi)]} A k_{t}^{\alpha} h_{t}^{1-\alpha} .
$$

In addition, we have $e_{t}^{X}=\theta_{t}^{X} w_{t} h_{t}=\beta \delta(1-\alpha+\phi) A k_{t}^{\alpha} h_{t}^{1-\alpha} /(\omega+\Omega)$, from which we can get

$$
e_{t}^{X}-e_{t}^{P}=\frac{\beta \delta A k_{t}^{\alpha} h_{t}^{1-\alpha}}{\omega+\Omega} \frac{\alpha \delta \Omega(1-\alpha+\phi)+\omega(1-\alpha)(1+\alpha \delta)}{\alpha \delta \Omega+\omega(1+\alpha \delta+\beta \delta \phi)}>0
$$

Further, it is straightforward to show that

$$
\frac{k_{t+1}^{P}}{k_{t+1}^{X}}=\frac{\omega+\alpha \delta \Omega /(1+\alpha \delta)}{\omega(1+\alpha \delta+\beta \delta \phi) / \Omega+\alpha \delta} .
$$

Since it can be verified that $(1+\alpha \delta+\beta \delta \phi) / \Omega<1$ and $\Omega /(1+\alpha \delta)>1$, obviously we have $k_{t+1}^{P} / k_{t+1}^{X}>1$.

Finally, it can be easily verified that $\left(h_{t+1}^{X} / h_{t}^{X}\right) /\left(h_{t+1}^{P} / h_{t}^{P}\right)>1$ holds when $\alpha=0$. Hence the proof of the first part.

The second part of the proof follows directly from the discussion under the proposition in the main text.

Proof of Proposition 2. First we need to note that the PAYG social security tax rate is non-negative if and only if $\omega \geq \widehat{\omega} \equiv \alpha \Omega /(1-\alpha)$. Then given $\omega \geqslant \widehat{\omega}$, it can be easily checked that

$$
\frac{e_{t}^{G}}{e_{t}^{X}}=\left(1+\frac{\omega}{\Omega}\right)(1-\alpha) \geq 1
$$

Hence the proof of the first part.

The proof of part (2) relies on the comparison of $e_{t}^{L}$ with $e_{t}^{P}$ and $e_{t}^{X}$ respectively.

(a) Here we compare between $e_{t}^{L}$ and $e_{t}^{P}$. It is straight forward to check that

$$
\frac{e_{t}^{L}}{e_{t}^{P}}=\frac{1-\alpha}{1+\delta+\beta \delta \phi}\left[1+2 \alpha \delta+\beta \delta \phi+\frac{\omega^{2}(1+\alpha \delta+\beta \delta \phi)+\alpha \delta \Omega^{2}}{\omega \Omega}\right],
$$

from which we know the comparison of $e_{t}^{L}$ with $e_{t}^{P}$ depends on the value of $\omega$. Taking derivative of $e_{t}^{L} / e_{t}^{P}$ with respect to $\omega$ yields

$$
\frac{\partial\left(e_{t}^{L} / e_{t}^{P}\right)}{\partial \omega}=\frac{1-\alpha}{1+\delta+\beta \delta \phi}\left(\frac{1+\alpha \delta+\beta \delta \phi}{\Omega}-\frac{\alpha \delta \Omega}{\omega^{2}}\right) .
$$

Evidently $e_{t}^{L} / e_{t}^{P}$ is convex in $\omega$ for all $t$, along with $e_{t}^{L} / e_{t}^{P} \rightarrow \infty$ as $\omega \rightarrow 0$ or $\omega \rightarrow \infty$. Hence either $e_{t}^{L} / e_{t}^{P}=1$ has two roots or $e_{t}^{L} / e_{t}^{P}>1$ for all $\omega$. It can be checked that $\widehat{\omega}$ is one of the solutions to $e_{t}^{L} / e_{t}^{P}=1$. Therefore there must exist another root of $e_{t}^{L} / e_{t}^{P}=1$. Denote $\widetilde{\omega}$ as the 
other root for $e_{t}^{L} / e_{t}^{P}=1$. By solving $e_{t}^{L} / e_{t}^{P}=1$, we have

$$
\widetilde{\omega}=\frac{\delta(1-\alpha) \Omega}{1+\alpha \delta+\beta \delta \phi} .
$$

Further, it can be checked that

$$
\left.\frac{\partial\left(e_{t}^{L} / e_{t}^{P}\right)}{\partial \omega}\right|_{\omega=\widehat{\omega}}=\frac{\alpha+\alpha \beta \delta \phi+2 \alpha \delta-\delta}{\alpha}
$$

Thus $\alpha+\alpha \beta \delta \phi+2 \alpha \delta-\delta \gtrless 0 \Leftrightarrow \widehat{\omega} \gtrless \widetilde{\omega}$ and since $e_{t}^{L} / e_{t}^{P}$ is convex in $\omega$, we must have $e_{t}^{L}<e_{t}^{P}$ for $\omega \in[\widetilde{\omega}, \widehat{\omega}]$ or $[\widehat{\omega}, \widetilde{\omega}]$ depending on which root is bigger, and clearly $e_{t}^{L}>e_{t}^{P} \forall \omega \notin[\widetilde{\omega}, \widehat{\omega}]$ or $[\widehat{\omega}, \widetilde{\omega}]$.

(b) Now we compare $e_{t}^{L}$ with $e_{t}^{X}$. It can be verified that

$$
\frac{e_{t}^{L}}{e_{t}^{X}}=\frac{\phi(1-\alpha)}{1+\delta+\beta \delta \phi}\left(\beta \delta+\frac{1+\alpha \delta+\omega}{1-\alpha+\phi}\right) .
$$

Evidently there exists a threshold value $\bar{\omega}$ where

$$
\bar{\omega}=\frac{(1+\delta+\alpha \phi \beta \delta)(1-\alpha+\phi)-\phi(1-\alpha)(1+\alpha \delta)}{\phi(1-\alpha)}
$$

such that $e_{t}^{L} \leq e_{t}^{X}$ holds if and only if $\omega \leq \bar{\omega}$. Just to mention that there is no reason to believe that the threshold values under (a) and (b) are the same - as shown above, they are different. Hence the proof. 